IZA DP No. 8368

Dynamic Incentive Effects of Heterogeneity in Multi-Stage Promotion Contests

Rudi Stracke

Uwe Sunde

August 2014 


\title{
Dynamic Incentive Effects of Heterogeneity in Multi-Stage Promotion Contests
}

\author{
Rudi Stracke \\ University of Munich (LMU) \\ Uwe Sunde \\ University of Munich (LMU), \\ IZA, CEPR and CESifo
}
Discussion Paper No. 8368
August 2014

\author{
IZA \\ P.O. Box 7240 \\ 53072 Bonn \\ Germany \\ Phone: +49-228-3894-0 \\ Fax: +49-228-3894-180 \\ E-mail: iza@iza.org
}

\begin{abstract}
Any opinions expressed here are those of the author(s) and not those of IZA. Research published in this series may include views on policy, but the institute itself takes no institutional policy positions. The IZA research network is committed to the IZA Guiding Principles of Research Integrity.

The Institute for the Study of Labor (IZA) in Bonn is a local and virtual international research center and a place of communication between science, politics and business. IZA is an independent nonprofit organization supported by Deutsche Post Foundation. The center is associated with the University of Bonn and offers a stimulating research environment through its international network, workshops and conferences, data service, project support, research visits and doctoral program. IZA engages in (i) original and internationally competitive research in all fields of labor economics, (ii) development of policy concepts, and (iii) dissemination of research results and concepts to the interested public.
\end{abstract}

IZA Discussion Papers often represent preliminary work and are circulated to encourage discussion. Citation of such a paper should account for its provisional character. A revised version may be available directly from the author. 
IZA Discussion Paper No. 8368

August 2014

\section{ABSTRACT \\ Dynamic Incentive Effects of Heterogeneity in Multi-Stage Promotion Contests}

This paper shows that the incentive effects of heterogeneity may be positive rather than negative in dynamic contests with multiple stages. In particular, the well-studied adverse effects of heterogeneity in static interactions are compensated by positive continuation-value and selection effects. Due to these positive dynamic incentive effects of heterogeneity that increase the incentives of relatively more able workers, heterogeneity is unlikely to be as detrimental as commonly perceived for incentives in organizations with multiple hierarchy levels. Heterogeneity of the workforce may even be optimal from the perspective of a firm that provides incentives using a multi-stage promotion contest.

JEL Classification: M52, J33

Keywords: promotion contest, multiple-stages, incentive provision, heterogeneity

Corresponding author:

Uwe Sunde

Seminar for Population Economics

University of Munich (LMU)

Schackstr. 4/IV

80539 München

Germany

E-mail: uwe.sunde@econ.Imu.de

\footnotetext{
* We would like to thank Steffen Altmann, Josse Delfgaauw, Philipp Denter, Matthias Kräkel, Dana Sisak, Dirk Sliwka, seminar participants at the University of Bonn, Innsbruck, München and St. Gallen, as well as participants of the Colloquium on Personnel Economics 2013 in Tübingen, EALE 2013 in Torino, and the Tournaments, Contests, and Relative Performance Evaluation conference in Fresno.
} 


\section{Introduction}

Career concerns are an important source of motivation in all organizations in which promotions are based on relative performance of employees. The basic idea of such 'career-concern' incentives is that the prospect of promotion to a more attractive and better-paid position within the same organization induces employees to work hard on their current job! Incentives of this type are at work in any organization with multiple ranks. In the majority of cases, the promotion contest within an organization is not explicitly designed and simply follows from a pyramidal organizational structure. Even in these cases, however, 'career-concern' incentives help to reduce monitoring costs if ordinal performance signals - that are sufficient for promotion incentives are obtainable at lower cost than cardinal measures of performance.

A potential downside of promotion contests is that the incentives they provide depend on the composition of the workforce. In particular, it is commonly believed that incentives in contest or tournament schemes are sub-optimally low whenever the competing workers are heterogeneous. However, the existing theoretical and empirical evidence on which this perception is based focuses on static one-shot interactions, while in reality promotion contests are inherently dynamic and typically involve heterogeneous workers. Intuitively, the next promotion is hardly ever the ultimate goal, but rather the prerequisite for future promotions to even more attractive positions from the perspective of a worker who enters an organization with multiple ranks.2

This paper shows that heterogeneity can be conducive for effort provision, and thus profitable for firms, in a promotion contest with multiple stages. To demonstrate this point, we consider a simple two-stage pairwise elimination contest with four heterogeneous workers and three hierarchy levels. In this setting, workers on the entry level initially compete in pairs for their first promotion. At the end of the first evaluation period, the two relatively best performing employees are promoted to the intermediate level, where they subsequently compete for the next promotion. The identity of the worker who is promoted to the top-level position is again determined by relative performance in the second evaluation period. To investigate how heterogeneity affects incentives in such a dynamic setting, we consider a theoretical model with highand low-ability workers. In particular, we compare the behavior of each worker type across homogeneous and heterogeneous configurations of the same model to determine how heterogeneity affects incentives.

\footnotetext{
${ }^{1}$ Evidence for the claim that performance pay is mainly reflected in promotions is provided by Baker, Gibbs, and Holmström $(1993,1994)$, for example.

${ }^{2}$ Evidence on this claim is provided by Haeck and Verboven (2012) who consider promotion dynamics in a European university. In the organization they consider, assistant professors who enter the university after their $\mathrm{PhD}$ must be promoted three times before they ultimately become full professor.
} 
In a first step, we analyze the incentive effect of heterogeneity in the last interaction of the promotion contest where the two workers that were initially promoted to the intermediate level compete for the final promotion to a top-level position. This effect turns out to be negative for both high- and low-ability workers, in line with the conventional wisdom that heterogeneity kills incentives. The conclusions are different when considering the entry level of the contest, however. While heterogeneity reduces incentives for low-ability workers, the opposite usually holds for high-ability workers. In particular, high-ability workers exert higher entry-level effort in heterogeneous configurations compared to the benchmark of a homogeneous configuration since future promotions are more likely to occur if there is a chance that the ability of future opponents is low. Therefore, the next promotion - the prerequisite for future promotions becomes more valuable for high-ability workers in heterogeneous configurations, such that their motivation on the entry level is higher. This positive dynamic incentive effect works through the continuation values of forward-looking agents.

In a second step, we compare expected effort provision of workers across both levels of the promotion contest in homogeneous and heterogeneous configurations. It immediately follows from the previous findings that the incentive effect of heterogeneity across both stages is strictly negative for low-ability workers. Incentives of high-ability workers, however, are higher in heterogeneous contests if the positive continuation value effect is sufficiently high, i.e., if the wage profile across hierarchy levels is sufficiently convex. In addition to this dynamic continuation value effect, there is a second dynamic effect that positively affects incentives for high-ability workers, namely a selection effect across hierarchy levels. Intuitively, the presence of low-ability workers in entry-level interactions increases the probability that high-ability workers receive the first promotion and thus reach the intermediate level. Consequently, expected effort provision by high-ability workers on the intermediate level increases from an ex-ante perspective.

Finally, we assess how these findings affect the optimal hiring decision of firms. In particular, we consider a stylized labor market in which promotion-contest incentives are combined with ability-adjusted market wages and show that a situation where the workforce is homogeneous in all firms cannot be an equilibrium. The reason is that profits of a firm that deviates to a combination of high- and low-ability workers are strictly higher than profits of firms with a homogeneous workforce, independent of the degree of heterogeneity or the wage profile across hierarchy levels. This implies that, in at least one configuration with heterogeneous workers, the increase in the effort of high-ability workers due to positive dynamic incentive effects of heterogeneity more than compensates for the corresponding effort reduction of low-ability workers.

The remainder of this paper is structured as follows. We first discuss the related literature 
in section 2, Section 3 introduces the formal model and derives the subgame perfect Nash equilibrium. Section 4 analyzes the incentive effect of heterogeneity both within each level and across levels. Section 5 discusses the implications of these effects for optimal hiring of firms, and section 6 investigates the robustness of our results. Section 7 concludes with practical implications of our findings.

\section{$2 \quad$ Related Literature}

The seminal paper on promotion contests by Lazear and Rosen (1981) argues that tournament contracts with two heterogeneous workers are inefficient. Intuitively, a designer cannot choose prizes such that the marginal benefit of effort equals its marginal costs for both workers. $3^{3}$ We abstract from efficiency in a contract theoretic sense and focus on the incentive effect of heterogeneity for a given structure of prizes. This effect governs the behavior of workers in any contest scheme, no matter how prizes are determined in a particular application. In this sense, we extend the theoretical analysis by Baik (1994) who discusses the adverse incentive effect of heterogeneity in a static two-player contest. To the extent that Baik's results form the basis for most existing empirical studies that try to measure the incentive effect of heterogeneity in contest or tournament environments, our results provide the empirical literature with novel testable hypotheses. While data on multi-stage elimination contests is easily available for sports tournaments, for example, existing studies either abstract from the dynamic structure of the competition, or they restrict attention to the incentive effect of heterogeneity on underdogs see Sunde (2009) and Brown (2011) for details. By isolating an effect of heterogeneity on incentives that is based on the strength of the co-workers that a worker expects to compete with in the future, this paper provides also a rationalization for peer effects that is based on a dynamic contest setting, complementing recent theoretical work by Kräkel (2008) and empirical evidence on the optimality of heterogeneous teams (Mas and Moretti, 2009).

The dynamic incentive effect of heterogeneity also matters for 'market-based' promotion tournaments where the wage increases associated with a promotion are determined by the competition of firms for talented workers $4^{4}$ Gürtler and Gürtler (2014) consider a one-shot tournament with heterogeneous workers and argue that heterogeneity may turn out to be optimal even in

\footnotetext{
${ }^{3}$ Lazear and Rosen (1981) also show that competitive handicaps can restore efficiency. Later work by O'Keeffe, Viscusi, and Zeckhauser (1984) and Bhattacharya and Guasch (1988) considers handicapping schemes that are less information sensitive and allow for self-sorting or workers. Gürtler and Kräkel (2010) show that type-specific prizes may serve as a substitute for strategic handicaps.

${ }^{4}$ Intuitively, within-firm promotions are an ability signal that allows workers to demand higher wages at competing firms - see Waldman (2013) for a comparison of 'classical' and 'market-based' promotion tournaments.
} 
this case if the adverse incentive effect of heterogeneity within the static interaction is overcompensated by a countervailing positive effect. The positive incentive effect of heterogeneity in their paper is caused by the signalling character of promotions in a 'market-based' tournament where changes in the ability assessment of workers lead to changes in the wage offered to a promoted worker $5^{5}$ Our results are complementary in that the positive dynamic effects of heterogeneity which we find are present in any multi-stage contest. In particular, they work on top of the positive effects that Gürtler and Gürtler (2014) find in a 'market-based' tournament with multiple stages.

The present paper also contributes to the growing literature on multi-stage contests. The seminal contribution on multi-stage promotion contest by Rosen (1986) investigates the properties that the structure of reward must satisfy to ensure incentive maintenance across stages. We take the structure of prizes as given and determine the incentive effect of heterogeneity for any given structure of rewards. Groh, Moldovanu, Sela, and Sunde (2012) consider the same contest structure that we analyze in this paper, but investigate the case of a perfectly discriminating all-pay auction. In contrast, we consider an imperfectly discriminating monitoring technology, which accounts for measurement errors and chance in the determination of winners in relative performance evaluation schemes. Apart from this technical difference, we focus on differences in individual behavior across homogeneous and heterogeneous settings, while Groh et al. (2012) compare aggregate performance measures across heterogeneous configurations. Similarly, Stracke (2013) compares aggregate effort across heterogeneous versions of one-stage and two-stage contests, but not across homogeneous and heterogeneous versions of the same structure as is done here. In line with both contributions, our results also suggest that the optimal organizational structure of promotion contests depends on the composition of the workforce and on the design of the contest. In this sense, the theoretical predictions derived in the present paper are informative for future research on the interface between organizational structure and tournament design, given that existing (experimental) evidence typically restricts attention to homogeneous workers, see, e.g., Orrison, Schotter, and Weigelt (2004).

Finally, our findings are relevant for the small literature on dynamic incentive effects. The present paper is similar to Holmström (1999) in that it investigates the effect of time on incentives. In particular, both papers share the idea that career concerns provide implicit incentives and solve moral hazard of employees. The underlying mechanisms are different, however. Wage

\footnotetext{
${ }^{5}$ Intuitively, the ability assessment and thus the post-promotion wage of a worker considered to be of low ability is considerably upgraded if she succeeds against a high-ability worker, while the opposite is true for a worker considered to be of high ability that loses against a low-ability worker.
} 
increases are caused by learning about the ability of employees in Holmström (1999), whereas wage increases in our model are associated with a promotion to higher ranks. Another study that considers dynamic incentive effects is Casas-Arce and Martinez-Jerez (2009). They analyze a multi-period contest where the same agents interact repeatedly and show that interim performance evaluations generate endogenous heterogeneity and reduce incentives. The crucial difference in our model is that the relative performance in any stage matters only for the promotion decision on this level, and not for future promotions to even higher levels.

\section{The Model}

\subsection{A Dynamic Promotion Contest with Heterogeneous Workers}

Consider the simplest multi-stage promotion contest with two stages and four workers. As depicted in Figure 1, the four workers on entry-level positions initially compete in pairs for a promotion to the intermediate level. Subsequently, the two workers who were promoted to intermediate-level positions compete for another promotion to the top level. For simplicity, we abstract from status concerns and assume that the wage increase associated with a promotion is the only source of motivation. The overall budget available for promotion rewards amounts to $B$, and the parameter $0 \leq s<0.5$ defines the wage profile across hierarchy levels. Upon promotion to the intermediate level, the wage increases by $\Delta_{1}=s \cdot B$; the wage increase associated with a promotion to the top level position amounts to $\Delta_{2}=(1-2 s) \cdot B$.

We assume that relative performance evaluations determine promotion decisions. Thus, workers are evaluated relative to their co-workers while working on their current position. The performance $q_{i}$ of worker $i \in\{1,2,3,4\}$ is determined by effort $x_{i}$ and chance $\epsilon_{i}$. For given effort levels $x_{j}$ and $x_{k}$ by two competing workers $j$ and $k$, worker $j$ is promoted with probability

$$
p_{j}\left(x_{j}, x_{k}\right)=\operatorname{Pr}\left(q_{j}>q_{k}\right)=\operatorname{Pr}\left(x_{j} \cdot \epsilon_{j}>x_{k} \cdot \epsilon_{k}\right),
$$

where $\epsilon_{j}$ and $\epsilon_{k}$ are independent draws from an exponential distribution with mean one. The multiplicative error structure delivers the analytically convenient Tullock (1980) lottery contest technology, according to which the promotion probability $p_{j}$ of worker $j$ in a pairwise interaction is equivalent to the ratio of own effort $x_{j}$ over the effort provided all workers who participate in 
Figure 1: Structure of the Promotion Contest

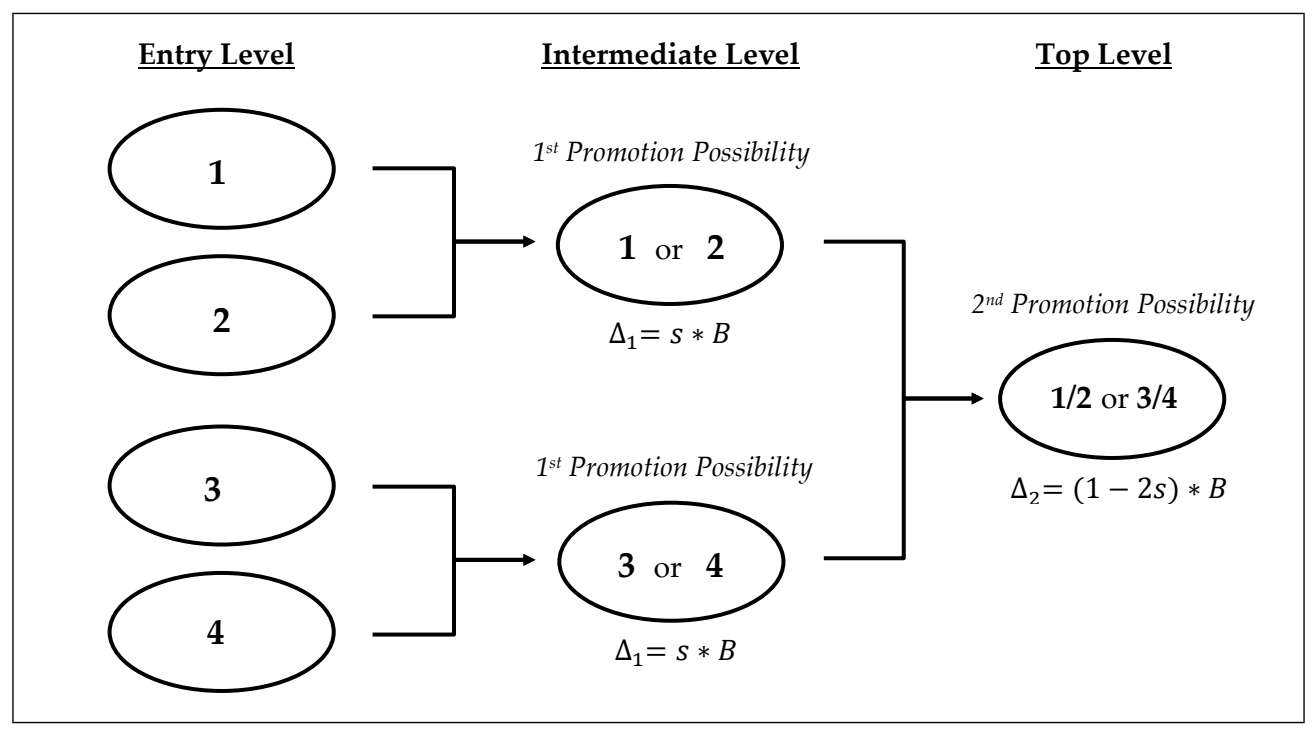

the respective competition. ${ }^{6}$ If worker $j$ competes with worker $k$,

$$
p_{j}\left(x_{j}, x_{k}\right)=\left\{\begin{array}{ccc}
\frac{x_{j}}{x_{j}+x_{k}} & \text { if } & x_{j}+x_{k}>0 \\
\frac{1}{2} & \text { if } & x_{j}+x_{k}=0
\end{array} .\right.
$$

Workers know that they are being evaluated. From the perspective of a worker, the promotion probability is increasing in own effort and decreasing in the effort provided by the opponent. The worker with the higher effort provision does not win with certainty, however, since the ordinal performance signal is noisy.

Workers may differ in their ability to perform in their job. In particular, we consider lowability workers (denoted L) with ability $a_{\mathrm{L}}$, and high-ability workers (denoted $\mathrm{H}$ ) with ability $a_{\mathrm{H}}>a_{\mathrm{L}}$. Moreover, we assume that the ability of a worker reduces the cost of providing effort, i.e., effort costs for a given level of effort $\bar{x}>0$ are lower for high-ability than for lowability workers. For simplicity, we employ a linear effort cost function and define effort costs as $c(a, x)=\frac{x}{a}$. To keep the theoretical analysis tractable and to focus on the incentive effect of heterogeneity, we assume that workers are risk neutral and that (ability) types are common

\footnotetext{
${ }^{6}$ For details on how to prove this equivalence, see Konrad (2009, p.52f).

${ }^{7}$ Instead of a setting with four different worker types, we consider the analytically simpler setting with only two types, since the ratio (or difference) of ability parameters gives a transparent and straightforward measure for the degree of heterogeneity. In contrast, it is not clear how the overall degree of heterogeneity would be determined in a contest with four types, where a change of the ability of intermediate types simultaneously increases and decreases heterogeneity to some other workers. Nevertheless, a solution of the model with up to four different worker types is available from the corresponding author upon request.
} 
Table 1: Equilibrium Efforts in the Competition for the $2^{\text {nd }}$ Promotion Possibility

\begin{tabular}{|c|c|c|c|}
\hline \multicolumn{2}{|c|}{ homogeneous competition } & \multicolumn{2}{|c|}{ heterogeneous competition } \\
\hline High Ability (H) & Low Ability (L) & High Ability (H) & Low Ability (L) \\
\hline$x_{2}^{*}(\mathrm{H} \mid \mathrm{HH})=\frac{a_{\mathrm{H}}(1-2 s) B}{4}$ & $x_{2}^{*}(\mathrm{~L} \mid \mathrm{LL})=\frac{a_{\mathrm{L}}(1-2 s) B}{4}$ & $x_{2}^{*}(\mathrm{H} \mid \mathrm{HL})=\frac{a_{\mathrm{H}}^{2} a_{\mathrm{L}}(1-2 s) B}{\left(a_{\mathrm{H}}+a_{\mathrm{L}}\right)^{2}}$ & $x_{2}^{*}(\mathrm{~L} \mid \mathrm{HL})=\frac{a_{\mathrm{L}}^{2} a_{\mathrm{H}}(1-2 s) B}{\left(a_{\mathrm{H}}+a_{\mathrm{L}}\right)^{2}}$ \\
\hline
\end{tabular}

knowledge.

The Subgame Perfect Nash Equilibrium is obtained through backward induction. Thus, we start with the competition on the intermediate level for promotion to the top-level position. Subsequently, we analyze the competition on the entry level for promotion to the intermediate level.

\subsection{Equilibrium Behavior of Workers on the Intermediate Level}

Depending on the number of high- and low-ability workers on the entry level, the competition on the intermediate level may be between homogeneous or heterogeneous workers: Either, both workers are high- or low-ability workers (denoted HH and LL, respectively), or workers are heterogenous, such that a high-ability worker competes with a low-ability worker (HL). The optimization problem of worker $j \in\{1,2\}$ with ability $a_{m}$ who competes with the $a_{n}$-ability worker $k \in\{3,4\}$ on the intermediate level (level 2) is defined as

$$
\max _{x_{j 2} \geq 0} \Pi_{j 2}\left(x_{j 2}, x_{k 2}\right)=\frac{x_{j 2}}{x_{j 2}+x_{k 2}}(1-2 s) B-\frac{x_{j 2}}{a_{m}}
$$

where $x_{j 2}$ and $x_{k 2}$ are the effort choices by workers $j$ and $k$ on level 2 , respectively, when competing for the wage increase $(1-2 s) B$, and $m, n=\{\mathrm{H}, \mathrm{L}\}$. Equilibrium effort choices in the homogeneous and the heterogeneous interactions are determined by first-order conditions. While the derivation is relegated to Appendix A.1, the resulting equilibrium choices are provided in Table 1. In this table, we define $x_{j 2}^{*}(m n):=x_{2}^{*}(m \mid m n)$ and $x_{k 2}^{*}(m n):=x_{2}^{*}(n \mid m n)$ since optimal behavior does not depend on the worker identity, but only on the types of interacting workers.

\subsection{Equilibrium Behavior of Workers on the Entry Level}

There are two parallel promotion contests on the entry level (level 1). To illustrate the structure of the optimization problem, consider worker 1 with ability $a_{m}$ who chooses entry-level effort $x_{11}$ 
to maximize her expected payoff, taking the effort choices of worker 2, 3, and 4 as given:

$$
\max _{x_{11} \geq 0} \Pi_{11}\left(x_{11}, x_{21} \mid x_{31}, x_{41}\right)=\frac{x_{11}}{x_{11}+x_{21}}\left[s B+\mathrm{CV}_{1}\left(x_{31}, x_{41}\right)\right]-\frac{x_{11}}{a_{m}}
$$

The optimization problem reveals that the prize for which worker 1 competes on the entry level is determined by two components: First, wages on the intermediate level exceed wages on the entry level by the amount $s B$ - this is the immediate reward for a promotion to the intermediate level. Moreover, a promotion to the intermediate level is necessary to participate in the competition for promotion to the top level. The continuation value $\mathrm{CV}_{1}\left(x_{31}, x_{41}\right)$ captures this dynamic component and is formally defined as follows:

$$
\mathrm{CV}_{1}\left(x_{31}, x_{41}\right)=\frac{x_{31}}{x_{31}+x_{41}} \Pi_{12}\left(x_{12}^{*}, x_{32}^{*}\right)+\frac{x_{41}}{x_{31}+x_{41}} \Pi_{12}\left(x_{12}^{*}, x_{42}^{*}\right)
$$

If worker 1 is promoted to the intermediate level (level 2), she will compete with worker 3 or 4 for the promotion to the top level (see Figure 1). This explains why the continuation value depends on $x_{31}$ and $x_{41}$ - these effort choices jointly determine the probability that worker 3 or 4 is promoted to the intermediate level. The respective probabilities are the weights that are attached to the equilibrium payoffs $\Pi_{12}\left(x_{12}^{*}, x_{32}^{*}\right)$ and $\Pi_{12}\left(x_{12}^{*}, x_{32}^{*}\right)$ that worker 1 can expect in a competition for the promotion to the top level with worker 3 or 4 . These equilibrium payoffs do not depend on the worker identity itself, but on the worker type. Intuitively, any worker is more likely to beat a low- than a high-ability opponent in the promotion contest on the intermediate level.

The optimization problems of workers 2, 3, and 4 have an analogous structure. Thus, the two separate promotion competitions on the entry level are mutually interdependent due to endogenously determined continuation values, which implies that equilibrium effort choices are characterized by a system of four first-order optimality conditions.

In the two-type model with high- and low-ability workers, there are six meaningful configurations of worker types: In addition to the two homogeneous options with high- or low-ability workers (denoted HHHH and LLLL), there are four alternative configurations with workers of both types. There may be three high-ability and one low-ability worker (HHHL), or one highability and three low-ability workers (HLLL), or two workers of each type. In the latter case, the two separate entry-level interactions could either be homogeneous (HHLL) or heterogeneous (HLHL). The formal derivation of equilibrium entry-level effort choices in these six configurations $C=\{$ LLLL , HLLL , HHLL , HLHL , HHHL , HHHH $\}$ is tedious and relegated to Appendix A.2. 
Figure 2: Incentive Effect of Heterogeneity on the Intermediate Level

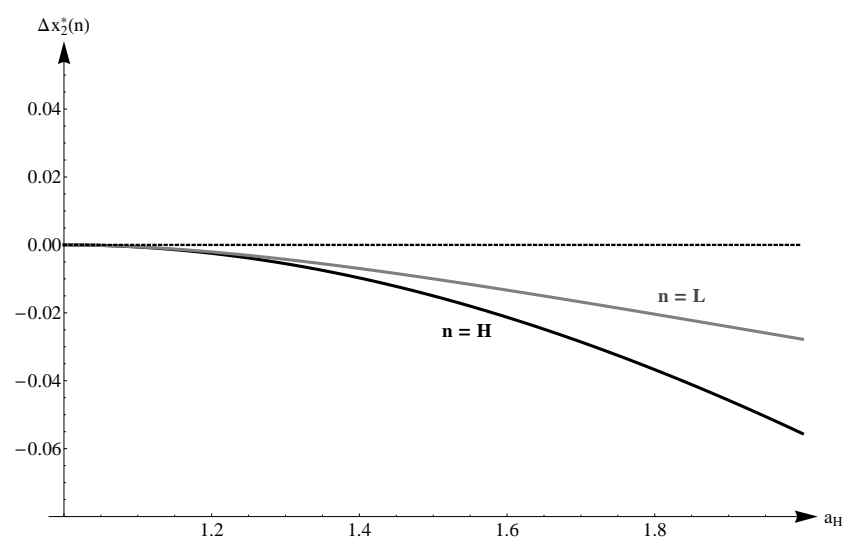

Note: The figure plots the incentive effect of heterogeneity for a high-ability worker, $x_{2}^{*}(\mathrm{H} \mid \mathrm{HL})-x_{2}^{*}(\mathrm{H} \mid \mathrm{HH})$, and the corresponding incentive effect for lowability workers, $x_{2}^{*}(\mathrm{~L} \mid \mathrm{HL})-x_{2}^{*}(\mathrm{~L} \mid \mathrm{LL})$, for $a_{\mathrm{L}}=1$ and $(1-2 s) B=1$.

\section{The Incentive Effect of Heterogeneity}

\subsection{Incentive Effect on the Intermediate Level}

To investigate how heterogeneity affects incentives of workers, we subsequently compare equilibrium effort choices of each worker type in homogeneous and heterogeneous interactions. Equilibrium effort choices by high- and low-ability workers both in homogeneous and heterogeneous promotion competitions on the intermediate level are provided in Table 1 . We define the incentive effect of heterogeneity for a worker of type $n \in\{\mathrm{H}, \mathrm{L}\}$ as

$$
\Delta x_{2}^{*}(n)=x_{2}^{*}(n \mid \mathrm{HL})-x_{2}^{*}(n \mid n n) .
$$

We find that $\Delta x_{2}^{*}(n)<0$ both for high- and low-ability workers, which implies that the incentive effect of heterogeneity is negative in the (essentially static) interaction on the intermediate level. Intuitively, low-ability workers realize that they are unlikely to overcome the ability advantage of their opponent and provide less effort than in a homogeneous competition. The high-ability worker can now afford to relax and reduces her effort as well. We summarize this finding as follows:

Proposition 1 (Incentive effect of heterogeneity on the intermediate level). The incentive effect of heterogeneity on the intermediate level, $\Delta x_{2}^{*}(n)$, is strictly negative for any $n \in\{H, L\}$.

Proof. See Appendix B. 
Figure 2 plots $\Delta x_{2}^{*}$ as a function of $a_{\mathrm{H}}$, the ability parameter of high-ability workers. The ability parameter of low-ability workers, $a_{\mathrm{L}}$, is normalized to one. The figure reveals two things: First, the negative effect is non-linear in the degree of heterogeneity. In particular, a marginal increase in the degree of heterogeneity has a more pronounced negative impact when heterogeneity is high. Second, the negative effect of heterogeneity seems to be more pronounced for high- than for low-ability workers. This finding holds only in absolute terms, however, and does not pertain to the percentage change of effort provision in response to variation in heterogeneity. Intuitively, effort by high-ability workers is higher than effort by low-ability workers, such that the absolute effect of heterogeneity differs across types even though the relative effect in terms of percentage changes is identical.

\subsection{Incentive Effect on the Entry Level}

Equilibrium-effort choices on the entry level depend on the number of types and their seeding across entry-level interactions. As mentioned before, there are six possible type configurations. The analysis is complicated by the fact that we must account both for the identity and the type of a worker whenever one interaction on the entry level is homogeneous, while the other one is heterogeneous. For example, the high-ability worker who competes against a low-ability worker behaves differently than the high-ability workers who compete with each other in configuration HHHL. We abstract from differences between workers of the same type subsequently and analyze the average incentive effect of heterogeneity for high- and low-ability workers in each particular configuration. In this case, the incentive effect of heterogeneity on the entry level for a worker of type $n \in\{\mathrm{H}, \mathrm{L}\}$ in the subset of heterogeneous configurations $C^{\text {het }}=\{$ HLLL , HHLL , HLHL , HHHL $\}$ is defined as

$$
\Delta x_{1}^{*}\left(n \mid C^{\text {het }}\right)=x_{1}^{*}\left(n \mid C^{h e t}\right)-x_{1}^{*}(n \mid n n n n),
$$

where $x_{1}^{*}\left(n \mid C^{h e t}\right)=\frac{\sum_{\eta} x_{t 1}^{*}\left(C^{h e t}\right)}{\# n}$, and $\eta$ is the set of type- $n$ workers.

It is important to account for two different sources of heterogeneity on the entry level: First, the ability of workers who compete against each other might be different, such that there is heterogeneity within an interaction. On the intermediate level, this is the only effect of heterogeneity that is present and according to Proposition 1 , the incentive effect of heterogeneity within an interaction is negative both for high- and low-ability workers. Second, the ability of workers may differ across interactions, such that different types compete in the two separate entry-level interactions. As will become clear in the subsequent discussion, the incentive effect of heterogeneity across interactions is positive for high-ability and negative for low-ability workers. 
To understand why heterogeneity across interactions affects the incentives of workers, it helps considering the incentives on the entry level of configuration HHLL. In this configuration, highand low-ability workers compete in separate interactions for the promotion to the intermediate level. Both pairwise interactions are between homogeneous workers, such that the only source of heterogeneity is across interactions. Consider first how this heterogeneity affects equilibrium effort choices of the two high-ability workers on the entry level. Both anticipate that the opponent on the intermediate level for the promotion to the top level will always be a low-ability type. Relative to the homogeneous configuration HHHH, any one of the high-ability workers in HHLL is thus more likely to outperform her competitor on the intermediate level. This raises the 'continuation-value' component of the promotion to the intermediate level in configuration HHLL compared to HHHH. Consequently, heterogeneity across interactions on the entry level increases the expected prize for which high-ability workers compete and thus their equilibrium effort choice. For low-ability workers, the 'continuation-value' effect due to heterogeneity across interactions works in the opposite direction. They anticipate that their opponent on the intermediate level will always be a high-ability worker, which implies that their chances to receive a promotion to the top level position are lower in configuration HHLL compared to LLLL. Consequently, the 'continuation-value' component of the promotion to the intermediate level is lower for lowability workers, and they will exhibit a lower equilibrium effort on the entry level compared to the homogeneous configuration.

Since both the within- and the across-interaction effect of heterogeneity are negative for low-ability workers, this must also hold for $\Delta x_{1}^{*}\left(\mathrm{~L} \mid C^{\text {het }}\right)$, the incentive effect of heterogeneity for low-ability workers on the entry level. The corresponding incentive effect $\Delta x_{1}^{*}(\mathrm{H} \mid C)$ for high-ability workers, however, is positive whenever the positive effect of heterogeneity across interactions dominates the negative effect of within-interaction heterogeneity.

Proposition 2 (Incentive effect of heterogeneity on the entry level). The incentive effect of heterogeneity on the entry level, $\Delta x_{1}^{*}\left(n \mid C^{\text {het }}\right)$, is

(a) strictly negative for $n=L$ and $C^{\text {het }}=\{H L L L, H H L L, H L H L, H H H L\}$.

(b) jointly determined by the positive 'continuation-value' effect across interactions and the negative 'within-interaction' effect of heterogeneity for $n=H$.

Proof. See Appendix B.

Figure 3 plots $\Delta x_{1}^{*}\left(n \mid C^{\text {het }}\right)$ for $n \in\{\mathrm{H}, \mathrm{L}\}$ and $C^{\text {het }} \in\{$ HLLL , HHLL , HLHL , HHHL $\}$ as a function of $a_{\mathrm{H}}$, the ability parameter of high-ability workers. The ability parameter of low-ability workers, 
Figure 3: Incentive Effect of Heterogeneity on the Entry Level

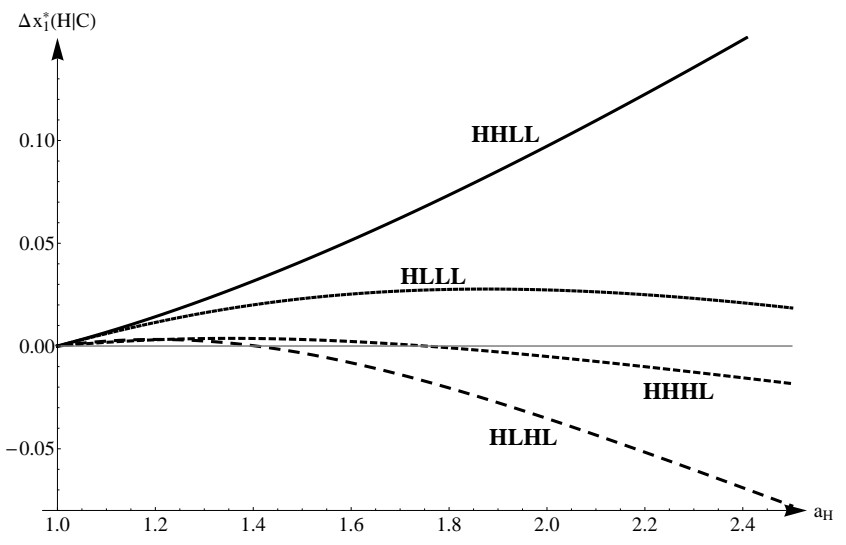

(a) High-Ability Workers

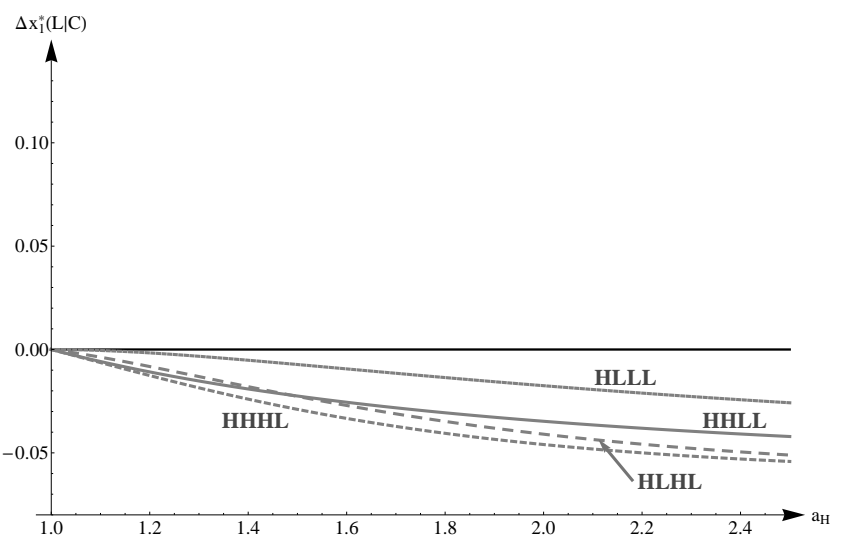

(b) Low-Ability Workers

Note: The figure plots the incentive effect of heterogeneity for a high-ability worker, $x_{1}^{*}\left(\mathrm{H} \mid C^{\text {het }}\right)-x_{1}^{*}(\mathrm{H} \mid \mathrm{HHHH})$, as well as the corresponding effect of a low-ability worker, $x_{1}^{*}\left(\mathrm{~L} \mid C^{\text {het }}\right)-x_{1}^{*}(\mathrm{~L} \mid \mathrm{LLLL})$, for $s=0, a_{\mathrm{L}}=1, B=1$, and $C^{\text {het }}=\{$ HLLL , HHLL , HLHL , HHHL $\}$.

$a_{\mathrm{L}}$, and the budget $B$ that is available for promotion rewards are normalized to one. Consider the incentive effect of heterogeneity for high-ability workers first, which is provided in panel (a). $\Delta x_{1}^{*}(\mathrm{H} \mid C)$ is positive in all configurations if ability differences are relatively small, which implies that the effect of heterogeneity across interactions dominates the within-interaction effect. This changes as $a_{\mathrm{H}}$ increases (while $a_{\mathrm{L}}$ is held constant) in all configurations except for HHLL. The within-interaction effect of heterogeneity becomes more important as the degree of heterogeneity increases, and ultimately dominates the across-interaction effect in all configurations. Configuration HHLL is an exception. Intuitively, within-interaction heterogeneity does not matter in HHLL where both entry-level interactions are homogeneous. Therefore, $\Delta x_{1}^{*}(\mathrm{H} \mid \mathrm{HHLL})$ remains positive throughout. In contrast, the within-interaction effect of heterogeneity is most pronounced in configuration HLHL where both interactions on the entry level are heterogeneous.

The incentive effect of heterogeneity on the entry level for low-ability workers is provided in panel (b) of Figure 3. The plot reveals that $\Delta x_{1}^{*}\left(\mathrm{~L} \mid C^{\text {het }}\right)<0$ in all configurations, in line with Proposition 2, The negative effect is most pronounced in configuration HHHL where the single low-ability worker not only faces a high-ability opponent on the entry level, but also knows for sure that, conditional receiving the promotion to the intermediate level, she will compete with another high-ability worker on the intermediate level for the promotion to the top level. The negative effect is least pronounced in configuration HLLL for similar reasons: The two low-ability workers compete with each other on the entry level and may even meet another low-ability 
worker on the intermediate level. Moreover, the low-ability worker who is in the unfortunate position to compete with a stronger opponent on the entry level anticipates that the ability of both potential opponents on the intermediate level is low.

The comparison of the incentive effect of heterogeneity across worker types in configuration HHLL delivers an important insight about the across-interaction effect of heterogeneity. In particular, the two panels of Figure 3 reveal that the absolute value of $\Delta x_{1}^{*}(\mathrm{H} \mid \mathrm{HHLL})$ substantially exceeds the absolute value of $\Delta x_{1}^{*}(\mathrm{~L} \mid \mathrm{HHLL})$. Consequently, the positive impact of the across-interaction effect of heterogeneity on incentives of high-ability workers dominates the corresponding negative impact on incentives of low-ability workers. Before we discuss the intuition for this relation, we summarize this finding in Lemma 1 for future reference.

Lemma 1 (Average effect of heterogeneity across interactions). The average incentive effect of 'across-interaction' heterogeneity is positive across high-and low-ability workers in configuration HHLL:

$$
\Delta x_{1}^{*}(H H L L):=2 \cdot \Delta x_{1}^{*}(H \mid H H L L)+2 \cdot \Delta x_{1}^{*}(L \mid H H L L)>0
$$

Proof. See Appendix B.

The intuition for the proof is as follows: First, heterogeneity implies that the share of the continuation value that accrues to high-ability (low-ability) workers is higher (lower) than in case of homogeneity. This will increase overall incentives on the entry level, as long as the sum of continuation values across types does not decrease. Intuitively, the marginal gain in effort by high-ability workers due to an increase of their prize by $1 \%$ exceeds the marginal loss in effort by low-ability workers when their prize decreases by $1 \%$. The reason is that marginal effort costs of high-ability workers are strictly lower than the corresponding costs for low-ability workers. Second, the joint continuation value of high- and low-ability workers must increase relative to a homogeneous benchmark, since joint costs of high- and low-ability workers in the intermediate level interaction of HHLL are lower due to heterogeneity. Intuitively, heterogeneity on the intermediate level reduces total effort by both workers in this interaction (Proposition 1), while the monetary value of the promotion to the top level remains constant. Taken together, the two arguments imply that net effect of 'across-interaction' heterogeneity on all workers is positive in HHLL. 


\subsection{Incentive Effect Across Both Levels}

The expected equilibrium effort across both levels of the promotion contest is a composite measure of effort on the entry level, and expected effort in the intermediate level. To illustrate the structure of this measure, consider the expected equilibrium effort of worker 1 across both levels in configuration $C, x^{*}(1 \mid C)$, which is formally defined as

$$
x^{*}(1 \mid C)=x_{11}^{*}(12 \mid C)+p(12 \mid C) \cdot\left[p(34 \mid C) \cdot x_{12}^{*}(13 \mid C)+p(43 \mid C) \cdot x_{12}^{*}(14 \mid C)\right],
$$

where $x_{11}^{*}(1 j \mid C)$ and $x_{12}^{*}(1 j \mid C)$ are the equilibrium effort choices of worker 1 in an interaction with worker $j$ on the entry and the intermediate level, respectively, and $p(1 j \mid C)$ is the probability that worker 1 beats worker $j$ on the entry level in the promotion contest with type configuration $C$. In what follows, we compare the average expected equilibrium effort across all workers of the same type in heterogeneous configurations with the corresponding expected equilibrium effort in the respective homogeneous configuration. The incentive effect of heterogeneity across both levels of the promotion contest is then formally defined as

$$
\Delta x^{*}\left(n \mid C^{h e t}\right)=x^{*}\left(n \mid C^{h e t}\right)-x^{*}(n \mid n n n n)
$$

where $n \in\{\mathrm{H}, \mathrm{L}\}$ and $C^{\text {het }} \in\{\mathrm{HLLL}, \mathrm{HHLL}, \mathrm{HLHL}, \mathrm{HHHL}\} . \Delta x^{*}\left(n \mid C^{\text {het }}\right)$ is determined by three components, which becomes clear when the average expected equilibrium effort of a type- $n$ worker is inserted in (6):

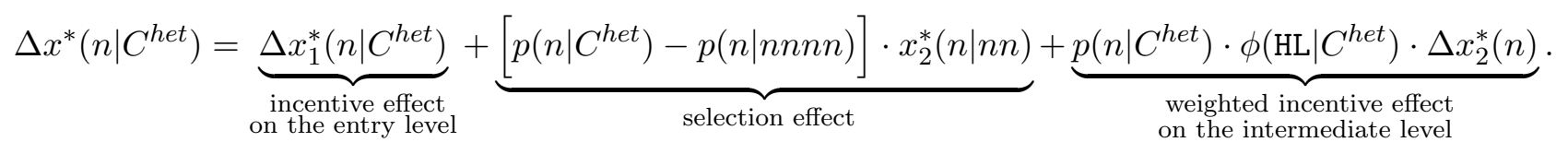

The first component of the incentive effect across both levels of the promotion contest is the incentive effect of heterogeneity on the entry level that was already discussed in subsection 4.2. Consider next the selection effect that depends on the heterogeneity-induced change in the probability of a promotion to an intermediate-level position. This effect matters in all heterogeneous configurations where workers of different types compete in at least one entrylevel interaction - and thus in all configurations but HHLL. To discuss the selection effect in more detail, let $p\left(n \mid C^{\text {het }}\right)$ be the average probability across type- $n$ workers for a promotion to the intermediate level in configuration $C^{\text {het }}$, and $p(n \mid n n n n)=0.5$ the respective probability in case of homogeneity. If the selection effect is at work, it increases the average probability of a promotion to an intermediate-level position above $p(\mathrm{H} \mid \mathrm{HHHH})=0.5$ for high-ability workers, and 
reduces the corresponding probability to a value below $p($ L ILLLL $)=0.5$ for low-ability workers. The change of this probability matters for expected equilibrium effort across both levels of the promotion contest, since it is a necessary condition for effort provision on the intermediate level to reach this hierarchy level in the first place. As intermediate-level effort by high-ability workers $x_{2}^{*}(\mathrm{H} \mid \mathrm{HH})$ exceeds the respective effort $x_{2}^{*}(\mathrm{~L} \mid \mathrm{LL})$ by low-ability workers in case of homogeneity which is the relevant benchmark for a ceteris paribus comparison - the net selection effect across all workers in the promotion contest is positive. We summarize this insight for future reference in Lemma 2 below:

Lemma 2 (Average selection effect of heterogeneity across types). The average selection effect of heterogeneity across types is non-negative in all heterogeneous configurations. Formally,

$$
z \cdot\left[p\left(\mathrm{H} \mid C^{h e t}\right)-0.5\right] \cdot x_{2}^{*}(\mathrm{H} \mid \mathrm{HH})+(4-z) \cdot\left[p\left(\mathrm{~L} \mid C^{\text {het }}\right)-0.5\right] \cdot x_{2}^{*}(\mathrm{~L} \mid \mathrm{LL}) \geq 0
$$

where $z$ is the number of high-ability workers in configuration $C^{\text {het }} \in\{H L L L, H H L L, H L H L, H H H L\}$.

Proof. See Appendix B.

The third component that matters for the incentive effect of heterogeneity across both levels is a probability-weighted version of the intermediate-level incentive effect discussed in Section 4.1. Intuitively, this last component accounts for all cases where a type- $n$ worker is promoted to the intermediate level - this occurs with probability $p\left(n \mid C^{\text {het }}\right)$ - and competes with a type- $m$ worker $(n \neq m)$ on the intermediate level. The configuration specific probability for this event is $\phi\left(\mathrm{HL} \mid C^{\text {het }}\right)$. In other words, the importance of the adverse incentive effect of heterogeneity on the intermediate level for the corresponding incentive effect across both levels depends on the probability $\phi\left(\mathrm{HL} \mid C^{h e t}\right)$ that the two workers who are promoted to the intermediate level turn out to be of different types in a particular configuration. This event occurs with probability one in configuration HHLL, for example, since the seeding of types on the entry level ensures that exactly one high- and one low-ability worker make it to the intermediate stage. The same event is unlikely in configuration HHHL, however.

Now that all components that matter for overall incentives in the promotion contest have been discussed, we analyze the incentive effect of heterogeneity across both level. Consider low-ability workers first. Heterogeneity reduces the incentives of low-ability workers on the intermediate and on the entry level in all heterogeneous configurations. The negative selection effect will work in the same direction, which implies that $\Delta x^{*}\left(\mathrm{~L} \mid C^{\text {het }}\right)<0$ unambiguously holds for $C^{\text {het }}=$ 
Figure 4: Incentive Effect of Heterogeneity across both Levels

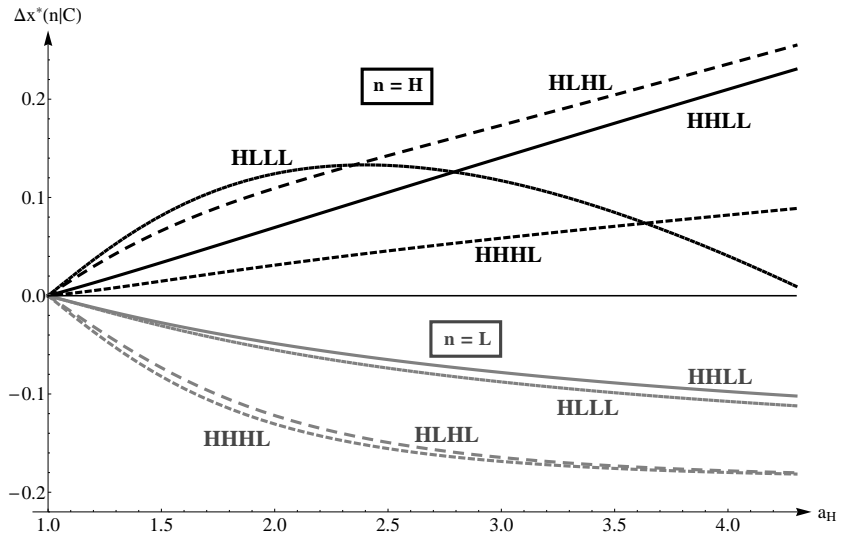

(a) convex wage profile $(s=0)$

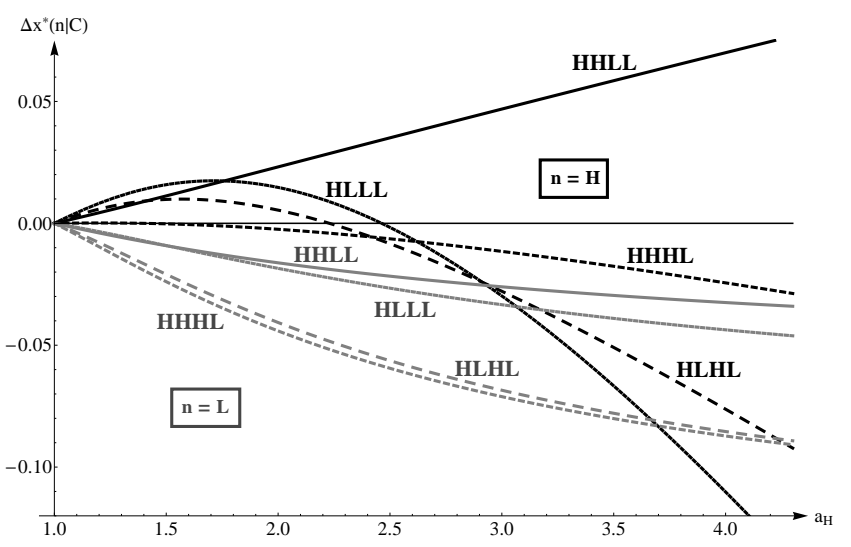

(b) linear wage profile $(s=1 / 3)$

Note: The figure plots the incentive effect of heterogeneity for a worker of type $n \in\{\mathrm{H}, \mathrm{L}\}, x^{*}\left(n \mid C^{\text {het }}\right)-x^{*}(n n n n)$, where $C^{\text {het }}=\{$ HLLL, HHLL , HLHL , HHHL $\}$, for $a_{\mathrm{L}}=1$ and $B=1$.

\{HLLL , HHLL , HLHL , HHHL . Consider next how heterogeneity affects the behavior of high-ability workers: (i) The incentive effect on the entry level may be positive or negative (Proposition 2), depending on the relative strength of within- and across-interaction heterogeneity effects; (ii) the selection effect is always positive; and (iii) the incentive effect on the intermediate level is always negative (Proposition 1). Consequently, the sign of the joint effect $\Delta x^{*}\left(\mathrm{H} \mid C^{\text {het }}\right)$ depends on the relative strengths of these countervailing effects. We summarize these findings below:

Proposition 3 (Incentive effect of heterogeneity across both levels). The incentive effect of heterogeneity across both levels, $\Delta x^{*}\left(n \mid C^{\text {het }}\right)$, is

(a) strictly negative for $n=L$ and $C^{\text {het }}=\{H L L L, H H L L, H L H L, H H H L\}$.

(b) jointly determined by a negative 'within-interaction' and a positive 'across-interaction' incentive effect on the entry level, a positive selection effect across levels, and a negative incentive effect on the intermediate level for $n=H$.

Proof. See Appendix B.

Figure 4 plots $\Delta x^{*}\left(n \mid C^{\text {het }}\right)$ for $n \in\{\mathrm{H}, \mathrm{L}\}$ and $C^{\text {het }} \in\{$ HLLL , HHLL , HLHL , HHHL $\}$ as a function of $a_{\mathrm{H}}$, the ability measure of high-ability workers. As in previous figures, the ability of lowability workers, $a_{\mathrm{L}}$, and the budget $B$ that is available for promotion rewards are fixed at one. 
Consider first panel (a) of Figure 4, where $s=0$ such that the wage profile is convex.$^{8}$ The figure reveals that the incentive effect of heterogeneity across both levels for low-ability workers is negative in all configurations: The adverse effect of heterogeneity is least pronounced in configuration HHLL where the selection effect is absent, and most pronounced in HLLL where both the selection and the 'continuation-value' effect reduce incentives of low-ability workers. Incentives of high-ability workers are positively affected by heterogeneity in all configurations but HLLL. Configuration HLLL nicely illustrates that different and countervailing forces are at work for high-ability workers: For low degrees of heterogeneity, the positive selection effect and the positive 'continuation-value' effect jointly dominate the negative 'within-interaction' effects on the entry and the intermediate level. This changes as heterogeneity increases, however - a high degree of heterogeneity induces the single high-ability worker to reduce effort both in the heterogeneous entry-level and in the heterogeneous intermediate-level interaction, such that the negative 'within-interaction' effect of heterogeneity on both stages starts to dominate selection and 'continuation-value' effects.

Next, consider panel (b) of Figure 4 where the wage profile is linear $(s=1 / 3)$ rather than convex - the prize associated with a promotion to the intermediate level and to the top level is exactly the same. Relative to the case depicted in panel (a), the promotion to the intermediate level is therefore more attractive in panel (b), while the opposite holds for the promotion to the top level. Workers react to this change in the structure of rewards by providing more effort on the entry and less effort on the intermediate level, which affects $\Delta x^{*}\left(n \mid C^{h e t}\right)$ for workers of either type. The incentive effect of heterogeneity across both levels for high-ability workers is now more likely to be negative - positive heterogeneity effects are weaker, while negative effects are equally strong or even stronger: First, the continuation value is less important due to the now lower value of the promotion to the top level. Second, selection to the intermediate level is less important for expected effort across both stages, since effort on the intermediate level is lower. Finally, the negative 'within-interaction' effect of heterogeneity on the entry level is stronger, since entry level effort is relatively more important. In line with these arguments, panel (b) of Figure 4 reveals that $\Delta x^{*}\left(\mathrm{H} \mid C^{\text {het }}\right)$ becomes negative for high degrees of heterogeneity in all configurations except configuration HHLL, where both the 'within-interaction' effect of heterogeneity on the entry level and the selection effect are absent. However, even in configuration HHLL, the positive incentive effect of heterogeneity across both levels is lower for $s=1 / 3$ than for $s=0$. Finally, panel (b) of Figure 4 reveals that low-ability workers benefit from the flatter wage profile: Both

\footnotetext{
${ }^{8}$ For $s=0$, the full budget $B$ available for promotions is awarded to the worker who is promoted to the top-level position, while there is no separate prize for promotion to the intermediate level.
} 
the negative 'continuation-value' and the negative selection effect of heterogeneity are weaker for $s=1 / 3$ than for $s=0$, such that the adverse incentive effect of heterogeneity across both levels for low-ability workers, $\Delta x^{*}\left(\mathrm{~L} \mid C^{\text {het }}\right)$, is less negative.

\section{The Optimal Skill Mix in Promotion Contests}

\subsection{A Simple Labor Market Model with Promotion Incentives}

In this section, we assess the implications of the previous results on the hiring decisions of firms. To focus ideas, consider a stylized labor market in which price-taking firms compete for high-ability and low-ability workers. Firms are homogeneous and share the organizational structure depicted in Figure 1. In each firm, workers receive a fixed, type-specific wage and compete for the promotion to better paid jobs inside the same organization. In particular, workers are evaluated relative to their co-workers and, depending on their relative performance, are either promoted at the end of each evaluation period or continue to work on their current position. We thus consider a setting where career concerns provide tournament like incentives and help to reduce moral hazard of employees. Arguably, incentives of this type are at work in almost any employment relationship. In most cases, 'career-concern' incentives will be combined with an additional incentive scheme, a minimum performance standard that must be met to keep the job, for example, or an 'up-or-out' policy which forces non-promoted workers to leave the organization. We subsequently abstract from this additional source of incentive provision and focus on the performance effect caused by career concerns of employees and the resulting competition for promotion.

Assume that each firm hires workers on the labor market for its four entry level positions, where they work initially in period 1. Based on their relative performance, two of these four workers on the entry level are promoted to the intermediate level at the beginning of period 2, and one of these two workers on the intermediate level is promoted to the top level position in period 3. Output of each worker in any period depends on effort and chance 9 For simplicity, we assume that workers who are not promoted at some point stay on their respective level until period 3 is over 10 We further assume that labor is the only input in production, and

\footnotetext{
${ }^{9}$ Recall that we consider a multiplicative error structure which implies $q_{t i}=x_{t i} \cdot \epsilon_{t i}$, where $\epsilon_{t i}$ is the random component drawn from an exponential distribution with mean one. See the promotion contest model discussed in section 3 for details.

${ }^{10}$ This assumption does not affect our results, since we maintain this assumption across homogeneous and heterogeneous configurations. In particular, our results remain unchanged if we consider an 'up-or-out' promotion contest instead.
} 
that aggregate production of a firm is additively separable in effort across workers, levels, and periods.

\subsection{The Hiring Decision of Firms}

Each firm hires workers on the labor market for the four entry-level positions, taking the period fixed wage $\omega_{n}$ for a worker of type $n \in\{\mathrm{H}, \mathrm{L}\}$ as given. Thus, we abstract from adverse selection in hiring and assume that worker-types are perfectly observable - this assumption keeps the theoretical analysis tractable and allows us to focus on the incentive effect of heterogeneity. The firm chooses the configuration $\mathcal{C} \in\{$ LLLL , HLLL , HHLL , HLHL , HHHL , HHHH $\}$ of worker types on the entry level that maximizes expected profits $\Psi(\mathcal{C})$. Let $z \in\{0,1,2,3,4\}$ be the number of highability workers in configuration $\mathcal{C}$, and $4-z$ the corresponding number of low-ability workers. Then, the expected profits $\Psi(\mathcal{C})$ of an arbitrary firm are formally defined as follows:

$$
\Psi(\mathcal{C})=z \cdot[V \cdot \underbrace{E\{q(\mathrm{H} \mid \mathcal{C})\}}_{x(\mathrm{H} \mid \mathcal{C})}-3 \cdot \omega_{\mathrm{H}}]+(4-z) \cdot[V \cdot \underbrace{E\{q(\mathrm{~L} \mid \mathcal{C})\}}_{x(\mathrm{~L} \mid \mathcal{C})}-3 \cdot \omega_{\mathrm{L}}]-B,
$$

where $V$ is the output price, $q(n \mid \mathcal{C})$ and $x(n \mid \mathcal{C})$ are total expected output and effort, respectively, of a type- $n$ worker across periods, $\omega_{n}$ is the fixed wage of a type- $n$ worker in any period, and $B$ is the total amount of prize money available for promotions ${ }^{11}$ For simplicity, we assume that all firms devote the same amount $B$ to bonus payments and choose the same wage profile $s$, which then implies that the respective wages for the two worker types must be identical across firms.

Since total output (or effort) of high-ability workers is always higher than the corresponding output of low-ability workers, the optimal configuration for a firm depends on the relative price of high- and low-ability workers, i.e., on the exogenous wages for workers of each type. These wages are jointly determined by the supply of high- and low-ability workers, and by the demand for workers of either type by all other firms. Thus, it is not possible to determine the optimal configuration for each firm without further assumptions on the number of firms and workers of either type. It is not necessary to determine the optimal configuration for each firm to assess whether a homogeneous or a heterogeneous workforce is desirable in multi-stage promotion contests, however. Instead, we subsequently investigate whether any firm has an incentive to hire a heterogeneous workforce in a situation where the workforce in all other firms is homogeneous.

\footnotetext{
${ }^{11}$ In general, firms can attract workers both through fixed wages and through the prize associated with a promotion. In reality, both components are certainly relevant for the decision of workers to accept a particular offer.
} 


\subsection{The Optimal Skill Mix}

To have a transparent benchmark, consider a situation where all firms employ a homogeneous workforce. To ensure that there is a positive demand for workers of either type, we assume that the wages for high- and low-ability workers are determined on the market such that firms are indifferent between hiring only high-ability or only low-ability workers. Formally, this implies that fixed wages $\omega_{\mathrm{L}}$ and $\omega_{\mathrm{H}}$ satisfy the condition $\Psi(\mathrm{LLLL})=\Psi(\mathrm{HHHH})=\tilde{\Psi} \geq 0$, which holds if and only if

$$
\omega_{\mathrm{L}}^{*}=\frac{V \cdot x(\mathrm{~L} \mid \mathrm{LLLL})-1 / 4(B+\tilde{\Psi})}{3} \quad \text { and } \quad \omega_{\mathrm{H}}^{*}=\frac{4 V \cdot x(\mathrm{H} \mid \mathrm{HHHH})-1 / 4(B+\tilde{\Psi})}{3}
$$

To avoid cases where unemployment is more attractive than employment for low-ability workers, we assume that the output price $V$ is sufficiently high to satisfy $\omega_{\mathrm{L}}^{*} \geq \bar{u}$, where $\bar{u}$ is the value of inactivity (or unemployment) for a worker independent of her type ${ }^{12}$ In order to assess whether this situation can be an equilibrium, consider next the optimization problem of one arbitrary firm $d$ that takes $\omega_{\mathrm{L}}^{*}$ and $\omega_{\mathrm{H}}^{*}$ as given. Can this firm ceteris paribus increase its expected profits by choosing one of the heterogeneous configurations instead? While existing results on static contests (or tournaments) suggest that homogeneity of participants is optimal, this turns out not to be the case in a dynamic multi-stage setting.

Proposition 4 (Optimal skill mix). For fixed wages $\omega_{L}^{*}$ and $\omega_{H}^{*}$, expected profits of a deviating firm d are strictly higher in at least one heterogeneous configuration $C^{\text {het }} \in\{H L L L, H H L L, H L H L, H H H L\}$ than in any one of the two homogeneous configurations, independent of the degree of heterogeneity and the steepness of incentives in the promotion contest:

$$
\text { For }\left\{\omega_{L}^{*}, \omega_{H}^{*}\right\}: \exists C^{\text {het }} \text { such that } \Psi_{d}\left(C^{\text {het }}\right)>\tilde{\Psi} \quad \forall 0 \leq s<0.5 \wedge 0<a_{L}<a_{H}
$$

Proof. See Appendix B.

According to Proposition 4, firm $d$ deviates from the choice of all other firms in terms of its configuration of workers and chooses the optimal heterogenous configuration if all other firms continue to employ a homogeneous workforce, i.e. if fixed wages satisfy (8) ${ }^{13}$ While the finding

\footnotetext{
${ }^{12}$ Since the expected payoff in any configuration is strictly positive even for low-ability workers, participation would even be optimal if $\omega_{\mathrm{L}}^{*}$ is slightly below $\bar{u}$. Generally, the value of $\omega_{\mathrm{L}}^{*}$ depends on the relation of $V(=$ value of output for the firm) and $\frac{1}{a_{\mathrm{L}}}$ (= marginal cost of effort for low-ability workers). Since $\frac{1}{a_{\mathrm{L}}}<\frac{1}{a_{\mathrm{H}}}$, $\omega_{\mathrm{L}}^{*} \geq \bar{u}$ also implies $\omega_{\mathrm{H}}^{*}>\bar{u}$.

${ }^{13}$ Importantly, both the amount for bonus payments $B$ and the incentive profile across stages that is characterized by $s$ remain constant across all firms to allow for a meaningful ceteris paribus variation of the workforce.
} 
that firms may benefit from a heterogeneous workforce is interesting in its own right, it is not sufficient to prove that a situation where all firms employ a homogeneous workforce cannot be an equilibrium. The reason is that both low-ability and high-ability workers must be willing to join firm $d$ that intends to employ workers of different types. This is not an issue for highability workers - they receive the same fixed wage and compete against weaker opponents for promotions of equal value in the deviating firm, such that they are unambiguously better off. Low-ability workers, however, face stronger opponents and have worse chances for promotions in firm $d$ - they are unambiguously worse off if their fixed wages remain unchanged. Consequently, the increase in expected profit for firm $d$ and the gain in expected payoffs for high-ability workers must be sufficiently large to allow for a compensation of low-ability workers through higher fixed wages that guarantees their voluntary participation. This is indeed the case.

Proposition 5 (Participation of low-ability workers). In at least one of the heterogeneous configurations that satisfy $\Psi_{d}\left(C^{\text {het }}\right)>\tilde{\Psi}$, the expected payoff gain due to a heterogeneous workforce for high-ability workers is larger than the corresponding expected payoff loss for low-ability workers.

Proof. See Appendix B.

Proposition 5 implies that the profit gain for firm $d$ due to heterogeneity is not even necessary to induce participation of low-ability workers in this firm. Instead, redistribution from high- to lowability workers through a revised pair of fixed wages can ensure that workers of either type are strictly better off in firm $d$ than in any firm with a homogeneous workforce. Consequently, firm $d$ may ceteris paribus increase its profits in a situation where all other firms hire a homogeneous workforce by choosing a particular heterogeneous configuration and fixed wages $\left\{\hat{\omega}_{\mathrm{L}}, \hat{\omega}_{\mathrm{H}}\right\}$ with $\hat{\omega}_{\mathrm{L}}>\omega_{\mathrm{L}}^{*}$ and $\hat{\omega}_{\mathrm{H}}<\omega_{\mathrm{H}}^{*}$. Taken together, this implies that a situation where all firms employ a homogeneous workforce cannot be an equilibrium in the labor market model we consider.

\subsection{Discussion}

The previous results suggest that firms and workers of either type may benefit from heterogeneity in a multi-stage promotion contest. This finding goes counter to the conventional wisdom that both 'underdogs' and 'favorites' slack off in heterogeneous interactions. To convey the intuition for these findings, we discuss the two propositions that imply that heterogeneity dominates homogeneity in the labor market we consider in turn. 
The effect of heterogeneity on profits. According to Proposition 4, a heterogeneous workforce allows a firm to increase its (expected) profits if fixed wages satisfy $\Psi($ LLLL $)=\Psi($ HHHH $)=$ $\tilde{\Psi}$. To understand the role of fixed wages for this finding, insert the formal expressions for fixed wages in the expected profit function of an arbitrary firm, as defined in (7). We then obtain:

$$
\Psi(\mathcal{C})=V \cdot\{z \cdot \underbrace{[x(\mathrm{H} \mid \mathcal{C})-x(\mathrm{H} \mid \mathrm{HHHH})]}_{\begin{array}{c}
\text { incentive effect of heterogeneity } \\
\text { for high-ability workers }
\end{array}}+(4-z) \cdot \underbrace{[x(\mathrm{~L} \mid \mathcal{C})-x(\mathrm{~L} \mid \mathrm{LLLL})]}_{\begin{array}{c}
\text { incentive effect of heterogeneity } \\
\text { for low-ability workers }
\end{array}}\}+\tilde{\Psi}
$$

The definition of fixed wages in (8) thus controls for the absolute ability effect on effort provision and is a prerequisite for a meaningful comparison of homogeneous and heterogeneous configurations. According to (9), the deviating firm $d$ prefers at least one heterogeneous configuration over the homogeneous configurations due to a positive aggregate incentive effect of heterogeneity across workers of both types. The two channels that positively affect $\Psi(\mathcal{C})$ are the previously discussed continuation value effect (across interactions) and the selection effect of heterogeneity. The impact of both effects on aggregate incentives across workers is positive at least in some configurations - see Lemmata 1 and 2 for details. In particular, Proposition 4 implies that these positive effects are stronger than the negative 'within-interaction' effects of heterogeneity (that reduce incentives both for high- and low-ability workers in any heterogeneous interaction on the entry or the intermediate level) in at least one heterogeneous configuration.

Figure 5 plots the difference in profits in heterogeneous configurations relative to the homogeneous benchmark as a function of $a_{\mathrm{H}}$ for two different within-firm wage profiles across hierarchy levels. In particular, the figure plots the weighted averages of the positive incentive effect across both levels for high-ability workers and the corresponding negative effect for low-ability types that is provided in Figure 4. A comparison of panels (a) and (b) delivers two important insights: First, with only one exception, the aggregate incentive effect of heterogeneity across worker types is positive in all heterogeneous configurations for certain degrees of heterogeneity in panel (a) of Figure 5, while the effect is only positive for configuration HHLL in panel (b) of Figure 5. Second, even in configuration HHLL, the positive effect of heterogeneity is stronger for convex incentives (with $s=0$ ) than for linear incentive profiles (with $s=1 / 3$ ). Both observations are due to the fact that the two positive dynamic effects of heterogeneity that affect high-ability workers, namely the 'across-interaction' effect of heterogeneity through continuation values and the selection effect across hierarchy levels, are less likely to dominate the negative 'within-interaction' effect when the reward structure is less convex. 
Figure 5: The Effect of Heterogeneity on Expected Profits

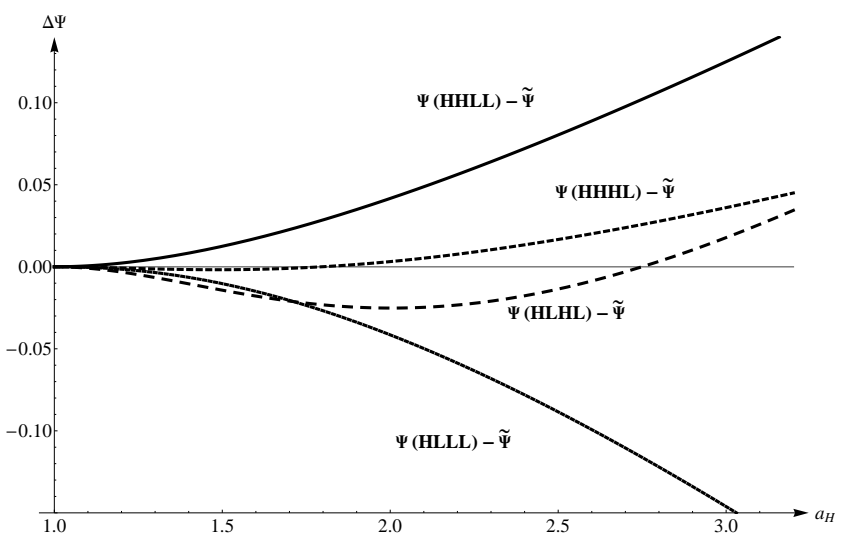

(a) convex wage profile $(s=0)$

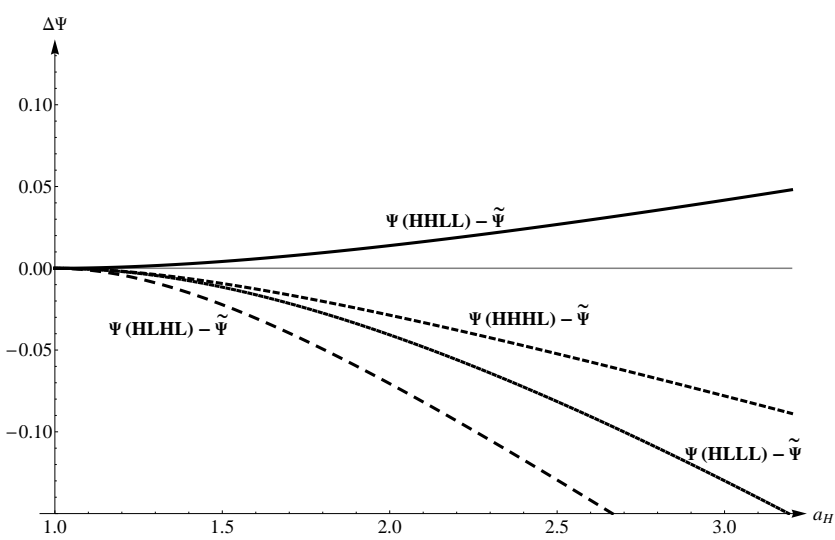

(b) linear wage profile $(s=1 / 3)$

Note: The figures plot the change in profits in heterogeneous configurations relative to the homogeneous benchmark as a function of $a_{\mathrm{H}}$ for different value of $s$, assuming $a_{\mathrm{L}}=1$ and $B=1$.

The effect of heterogeneity on total welfare. According to Proposition 5, the expected payoff across all participants of a promotion contest is higher in at least one heterogeneous configuration than in any one of the two homogeneous settings for fixed wages $\omega_{\mathrm{L}}^{*}$ and $\omega_{\mathrm{H}}^{*}$. Thus, heterogeneity does not only redistribute a fraction of the expected payoff from low-ability to high-ability workers, but delivers efficiency gains that make all workers better off and allow the firm to make higher profits at the same time.

As discussed before, heterogeneity has countervailing effects on incentives for high- and lowability workers, however. In particular, low-ability workers provide less effort in any heterogeneous configuration than in case of homogeneity, while high-ability workers provide more effort in heterogeneous configurations due to positive selection and 'continuation-value' effects. Therefore, heterogeneity shifts effort provision from workers with low-ability and high marginal costs to workers with high-ability and low marginal costs. As the value of effort to the firm is independent of the worker type who provides it, total welfare increases if heterogeneity induces a higher level of aggregate effort provision across workers 14 Intuitively, the presence of low-ability competitors can be seen as a cost-efficient way to increase incentives of high-ability workers.

\footnotetext{
${ }^{14}$ This mechanism does not depend on the assumption that heterogeneity enters through the cost function. The same applies if the marginal impact of effort on the firm's profits is type dependent, or if the valuation of a promotion differs across types. In this case, a worker's ability or 'productivity' is determined by a composite measure of heterogeneity that accounts for all these channels. Details are available upon request.
} 


\section{Robustness}

So far, the analysis restricted attention to a promotion contest with common knowledge of worker types, a particular monitoring technology, linear effort cost functions, firms with three hierarchy levels, and an additive production technology that rules out potential complementarities across workers and/or hierarchy levels within a firm. Subsequently, we discuss the role of these assumptions for the findings.

Common knowledge of types. The assumption that worker types are common knowledge has several implications: First, it rules out the problem of adverse selection, which allows focusing attention on the incentive effect of heterogeneity. Second, without this assumption an analytical solution of the model would be a contribution of independent value. While it has been shown by Fey (2008) that an equilibrium exists in a two player contest with two-sided type uncertainty, only special cases have been solved analytically so far ${ }^{15}$ Third, the assumption that worker types are common knowledge matters for the 'continuation-value' effect due to across-interaction heterogeneity on the entry level - this effect crucially depends on the information and expectations workers have about the type of the potential opponent in later stages of the promotion competition. However, as long as workers are rational and forward looking, the 'continuation-value' effect remains active. To illustrate this point, consider a firm with three high-ability and one low-ability worker (HHHL). In this case, the two high-ability workers who compete with each other on the entry level face uncertainty with respect to the opponent in the competition for the promotion to the top level. However, the 'continuation-value' effect is at work as long as the probability that the low-ability worker is promoted to the intermediate level remains positive in (the subgame perfect Nash) equilibrium.

Monitoring technology. With respect to the monitoring technology, one might think of two potential modifications: First, the error structure might be additive rather than multiplicative, as in the tournament model by Lazear and Rosen (1981) 16 Even though such a modification is likely to affect the strength of the two positive effects that heterogeneity may have for highability workers, namely the 'continuation-value' effect on the entry level and the selection effect across hierarchy level, both effects will still be at work. Almost any contest or tournament model is likely to satisfy the assumptions that are necessary for the presence of these effects ${ }^{17}$ The

\footnotetext{
${ }^{15}$ See Malueg and Yates (2004) or Ewerhart (2010) for details.

${ }^{16}$ Skaperdas (1996) provides an axiomatization of contest technologies with additive and multiplicative noise.

${ }^{17}$ For the 'continuation-value' effect, it must hold that effort provision is increasing in the prize, and that the expected payoff is increasing in the strategic disadvantage of the respective opponent. What matters for the
} 
presence of these effects does not imply automatically, however, that the aggregate incentive effect of heterogeneity across workers is positive. Whether or not this is the case in at least one heterogeneous configuration is likely to depend on distributional assumptions of the error term. The second possible modification of the monitoring technology is its precision, i.e., the relative importance of effort and randomness for the outcome. Consider the generalized Tullock contest success function

$$
p_{i}\left(x_{i}, x_{j}\right)=\left\{\begin{array}{ccc}
\frac{x_{i}^{r}}{x_{i}^{r}+x_{j}^{r}} & \text { if } & x_{i}^{r}+x_{j}^{r}>0 \\
\frac{1}{2} & \text { if } & x_{i}^{r}+x_{j}^{r}=0
\end{array} .\right.
$$

In this specification, the precision of the monitoring technology is determined through the parameter $r$. So far, we employed the analytically convenient lottery contest success function with $r=1$. In the general case, however, the relative importance of randomness for the outcome is decreasing in $r$, while the opposite holds for effort, with differences in effort being more decisive for higher levels of $r$. Numerical simulations of the the parameter range $0<r<1+\left(\frac{a_{\mathrm{L}}}{a_{\mathrm{H}}}\right)^{r}$ - for which the pure strategy equilibrium exists according to Nti (1999) - indicate that both the 'continuation-value' and the selection effect are present throughout. Moreover, we are able to show formally that the 'continuation-value' effect is sufficiently strong to overcompensate the adverse 'within-interaction' incentive effect of heterogeneity on the intermediate level in configuration HHLL 18

Cost function. In the analysis, it was assumed that the effort cost function of workers is linear and that the value $V$ of expected output to firms exceeds the marginal cost of effort for low-ability types. In this setting, production by workers of either type is efficient - the value of the output produced is strictly higher than the resulting (effort) costs independent of the level of production. This would be different in a model with convex cost functions where marginal effort costs increase with output. As long as the participation of low-ability workers is ensured, however, convex cost functions may affect our results in quantitative, but not in qualitative terms. First, the positive incentive effects of heterogeneity for high-ability workers do not depend on the shape of the cost function. Second, these effects will still increase total welfare, as the marginal effort costs are lower for high-ability than for low-ability workers for given values of $B$ and $s$.

selection effect is that high-ability workers provide (ceteris paribus) more effort on the intermediate level than low-ability workers.

${ }^{18}$ See Appendix C for details, where we solve configuration HHLL for the generalized Tullock CSF and show that the aggregate incentive effect of heterogeneity across workers is positive in this configuration in any pure strategy equilibrium. 
Firm size. The analysis in the main text of this paper considers the simplest case of a firm with multiple promotion possibilities, namely a four-worker firm with three hierarchy levels and two promotion possibilities. In reality, however, the number of hierarchy levels is likely to be higher. This simplification is unlikely to change our findings that (a) dynamic incentive effects of heterogeneity may positively (negatively) affect the effort of high-ability (low-ability) workers, and that (b) the net effect across workers of different types may turn out to be positive. As in the simple four-worker case considered here, the relative strength of countervailing effects and thus the likelihood of a positive aggregate incentive effect of heterogeneity will depend on the configuration of types on the entry level. To illustrate this argument, consider an eight-worker firm with an equal number of high- and low-ability workers. It is straightforward to show that the aggregate incentive effect of heterogeneity across workers is positive in a configuration where only the top level interaction is heterogeneous, analogous to the configuration HHLL. Intuitively, the adverse 'within-interaction' effect of heterogeneity on the top level remains unchanged as the number of workers in previous stages increases, while the positive 'continuation-value' effect in previous interactions is even stronger, as it carries over to additional homogeneous interactions between high-ability workers. Obviously, the aggregate incentive effect of heterogeneity may turn out to be negative in the same firm if the initial configuration of worker types leads to a higher number of heterogeneous interactions, as in an extended version of configuration HLHL, for example. In the latter case, the aggregate incentive effect of heterogeneity across workers is likely to depend on the steepness of incentives and on the degree of heterogeneity between high-ability and low-ability workers, just as in the four-worker setting.

Production technology. The production function neither affects the positive effect of heterogeneity on the entry level through continuation values nor the negative 'within-interaction' effect on any level. However, the assumption that the value of effort for the firm is independent of the level where effort is provided and is additively separable across workers matters in so far as the distribution of effort across workers and stages differs between homogeneous and heterogeneous configurations. In particular, all workers provide the same effort (at least in expected terms) in any homogeneous configuration, while low-ability workers provide less effort than high-ability workers in any heterogeneous configuration. This might be undesirable if complementarities across workers matter for total output. Moreover, heterogeneity changes the relative importance of entry-level and intermediate-level effort for total effort provision across hierarchy levels relative to homogeneous configurations for a given steepness of incentives $s$. When effort provision in different hierarchy levels is not equally valuable, the optimal $s$ for a particular firm might 
depend on the composition of its workforce.

\section{Concluding Remarks}

The analysis in this paper shows that the incentive effects of heterogeneity may be positive rather than negative in dynamic contests with multiple stages. Even though we find that the wellknown adverse incentive effects of heterogeneity discussed in the literature on static interactions are still present, they are often overcompensated by countervailing positive incentive effects in dynamic contest with multiple stages. Taken literally, our results suggest that heterogeneity is beneficial rather than detrimental in particular configurations of dynamic promotions contests. As previously discussed, however, this latter finding might depend on simplifying assumptions in the theoretical analysis. The more general and robust implication of our results is that incentive effects of heterogeneity are less detrimental than commonly perceived in multi-stage contests than in static one-shot interactions for two reasons. First, selection across stages implies that high-ability workers are much more likely to reach higher ranks, as was already verbally discussed (but not formally analyzed) in previous work 19 Second, the presence of low-ability workers in the field of competitors increases the continuation value component of promotions for forwardlooking high-ability workers and boosts their incentives in previous stages of the competition. Basically, the positive continuation value effect sets in whenever the selection mechanism fails.

The main implication for practitioners is that the available evidence on adverse incentive effects of heterogeneity in static interactions is not necessarily relevant for organizations with multiple hierarchy levels and heterogeneous employees that rely on career-concern incentives, given that promotion contests that are inherently dynamic. The insight that positive incentive effects of heterogeneity crucially depend on the dynamic nature of the competition implies, however, that human resource management (HRM) should inform employees on the entry level about typical career paths within the organization. In particular, HRM should highlight that the next promotion is always the prerequisite for any future promotion to higher ranks to make these intermediate promotions more attractive. ${ }^{20}$ In addition, the results of this paper show that incentive effects of heterogeneity in relative performance evaluation schemes depend on the organizational structure. Consequently, firms might want to take details of their organizational

\footnotetext{
${ }^{19}$ According to Rosen (1986), "the inherent logic [of promotion contests] is to determine the best contestants and to promote survival of the fittest" (p.701).

${ }^{20}$ Interestingly, anecdotal evidence from law and consulting firms where career-concern incentives are particularly important indicates that these firms already follow this suggestion. When one of the authors applied for an internship at a consultancy firm on a job fair, he was directly informed about both the typical time horizon and the common intermediate positions that precede the final promotion to the level of 'fully associated partner'.
} 
structure into account when designing (optimal) incentive schemes, or jointly optimize along both dimensions.

Ultimately, the practical relevance of the dynamic incentive effects that are analyzed in this paper is an empirical question. While several empirical studies already suggest that heterogeneity may have positive effects due to psychological factors (see, e.g., Chen, Ham, and Lim, 2011), it remains yet to be shown that the incentive effect of heterogeneity can become positive even when decision makers are forward-looking expected payoff maximizers. The observation by Brown and Minor (2014) that outcomes in the current stage of a multi-stage contest depend on the expected strength of future competitors is suggestive in this direction. Even though this does not automatically imply that dynamic effects compensate negative 'within-interaction' effects of heterogeneity, it at least indicates that decision makers strategically react changes of their continuation value as we assume in our model. 


\section{References}

BAIK, K. (1994): "Effort Levels in Contests with Two Asymmetric Players," Southern Economic Journal, 61, 367-378.

Baker, G. P., M. GibBs, And B. Holmström (1993): "Hierarchies and Compensation," European Economic Review, 37, 366-378.

Baye, M. R., D. Kovenock, and C. G. De Vries (1994): "The Solution to the Tullock Rent-Seeking Game when R>2: Mixed-Strategy Equilibria and Mean Dissipation Rates," Public Choice, 81, 363-380.

Bhattacharya, S., And J. L. Guasch (1988): "Heterogeneity, Tournaments, and Hierarchies," Journal of Political Economy, 96, 867-881.

Brown, J. (2011): "Quitters Never Win: The (Adverse) Incentive Effects of Competing with Superstars," Journal of Political Economy, 119, 982-1013.

Brown, J., And D. Minor (2014): "Selecting the Best: Spillover and Shadows in Elimination Tournaments," Management Science, forthcoming.

Casas-Arce, P., and F. A. Martinez-Jerez (2009): "Relative Performance Compensation, Contests, and Dynamic Incentives," Management Science, 55, 1306-1320.

Chen, H., S. H. Ham, and N. Lim (2011): "Designing Multiperson Tournaments with Asymmetric Contestants: An Experimental Study," Management Science, 57, 864-883.

Cornes, R., and R. Hartley (2005): "Asymmetric Contests with General Technologies," Economic Theory, 26, 923-946.

Ewerhart, C. (2010): "Rent-Seeking Contests with Independent Private Values," University of Zurich Working Paper 490.

FEY, M. (2008): "Rent-Seeking with Incomplete Information," Public Choice, 135, 225-236.

Groh, C., B. Moldovanu, A. Sela, and U. Sunde (2012): "Optimal Seedings in Elimination Tournaments," Economic Theory, 49, 59-80.

Gürtler, M., And O. Gürtler (2014): "The Optimality of Heterogeneous Tournaments," Journal of Labor Economics, forthcoming. 
Gürtler, O., ANd M. KRÄKEL (2010): "Optimal Tournament Contracts for Heterogeneous Workers," Journal of Economic Behavior and Organization, 75, 180-191.

Haeck, C., And F. Verboven (2012): "The Internal Economics of a University: Evidence from Personnel Data," Journal of Labor Economics, 30, 591-626.

Holmström, B. (1999): "Managerial Incentive Problems: A Dynamic Perspective," Review of Economic Studies, 66, 169-182.

KonRad, K. (2009): Strategy and Dynamics in Contests. Oxford University Press.

KräKEL, M. (2008): "Emotions in Tournaments," Journal of Economic Behavior and Organization, 67, 204-214.

Lazear, E. P., And S. Rosen (1981): "Rank-Order Tournaments as Optimal Labor Contracts," Journal of Political Economy, 89, 841-864.

Malueg, D. A., And A. J. Yates (2004): "Rent Seeking with Private Values," Public Choice, $119,161-178$.

Mas, A., And E. Moretti (2009): "Peers at Work," American Economic Review, 99, 112-145.

Ntı, K. O. (1999): "Rent-Seeking with Asymmetric Valuations," Public Choice, 98, 415-430.

O’Keeffe, M., W. K. Viscusi, and R. J. Zeckhauser (1984): "Economic Contests: Comparative Reward Schemes," Journal of Labor Economics, 2, 27-56.

Orrison, A., A. Schotter, And K. Weigelt (2004): "Multiperson Tournaments: An Experimental Examination," Management Science, 50, 268-279.

Rosen, S. (1986): "Prizes and Incentives in Elimination Tournaments," American Economic Review, 76, 701-715.

Skaperdas, S. (1996): “Contest Success Functions," Economic Theory, 7, 283-290.

Stracke, R. (2013): "Contest Design and Heterogeneity," Economics Letters, 121, 4-7.

Sunde, U. (2009): "Heterogeneity and Performance in Tournaments: A Test for Incentive Effects using Professional Tennis Data," Applied Economics, 41, 3199-3208. 
Tullock, G. (1980): "Efficient Rent-Seeking," in Toward a Theory of the Rent-Seeking Society. J.M. Buchanan and R.D. Tollison and G. Tullock (Eds.). Texas A\&M Press, College Station, p. $97-112$.

Waldman, M. (2013): "Classic Promotion Tournaments versus Market-Based Tournaments," International Journal of Industrial Organization, 31, 198-210. 


\section{Appendix}

\section{A Solving the Optimization Problem of Workers}

The relevant solution concept for optimal behavior in the two-stage promotion contest is Subgame Perfect Nash Equilibrium. The equilibrium is derived by backward induction, starting with the analysis of behavior in the competition for the $2^{\text {nd }}$ promotion possibility on the intermediate level, before considering the initial competition on the entry level.

\section{A.1 Competition on the Intermediate Level}

With workers of two different types, there are three potential interaction on the intermediate level, namely HH (two high-ability workers), LL (two low-ability workers), and HL (one highand one low-ability worker). The formal optimization problem of worker $i$ with ability $a_{i}$ who competes against worker $j \neq i$ on the intermediate level reads

$$
\max _{x_{i 2} \geq 0} \Pi_{i 2}\left(x_{i 2}, x_{j 2}\right)=\frac{x_{i 2}}{x_{i 2}+x_{j 2}}(1-2 s) B-\frac{x_{i 2}}{a_{i}}
$$

where $x_{i 2}$ and $x_{j 2}$ are the effort choices by workers $i$ and $j$, respectively. Equilibrium effort in the homogeneous intermediate level interactions $\mathrm{HH}$ and LL reads

$$
x_{2}^{*}(\mathrm{H} \mid \mathrm{HH})=\frac{(1-2 s) a_{\mathrm{H}} B}{4} \quad \text { and } \quad x_{2}^{*}(\mathrm{~L} \mid \mathrm{LL})=\frac{(1-2 s) a_{\mathrm{L}} B}{4},
$$

respectively; effort of strong and weak workers in the heterogeneous intermediate level interaction HL is defined as

$$
x_{2}^{*}(\mathrm{H} \mid \mathrm{HL})=\frac{(1-2 s) a_{\mathrm{H}}^{2} a_{\mathrm{L}} B}{\left(a_{\mathrm{H}}+a_{\mathrm{L}}\right)^{2}} \quad \text { and } \quad x_{2}^{*}(\mathrm{~L} \mid \mathrm{HL})=\frac{(1-2 s) a_{\mathrm{H}} a_{\mathrm{L}}^{2} B}{\left(a_{\mathrm{H}}+a_{\mathrm{L}}\right)^{2}} \text {. }
$$

Inserting equilibrium efforts in the objective functions of high- and low-ability workers delivers the expected value of the $2^{\text {nd }}$ promotion possibility; $\Pi_{2}(\mathrm{H} \mid \mathrm{HL}) \equiv \Pi_{2}\left(x_{2}^{*}(\mathrm{H} \mid \mathrm{HL}), x_{2}^{*}(\mathrm{~L} \mid \mathrm{HL})\right)$ and $\Pi_{2}(\mathrm{~L} \mid \mathrm{HL}) \equiv \Pi_{2}\left(x_{2}^{*}(\mathrm{~L} \mid \mathrm{HL}), x_{2}^{*}(\mathrm{H} \mid \mathrm{HL})\right)$ denote the expected equilibrium payoff of high- and lowability workers in the heterogeneous interaction $\mathrm{HL} ; \Pi_{2}(\mathrm{H} \mid \mathrm{HH}) \equiv \Pi_{2}\left(x_{2}^{*}(\mathrm{H} \mid \mathrm{HH}), x_{2}^{*}(\mathrm{H} \mid \mathrm{HH})\right)$ and $\Pi_{2}(\mathrm{~L} \mid \mathrm{LL}) \equiv \Pi_{2}\left(x_{2}^{*}(\mathrm{~L} \mid \mathrm{LL}), x_{2}^{*}(\mathrm{~L} \mid \mathrm{LL})\right)$ are the respective expected payoffs for high- and low-ability workers in the homogeneous interactions HH and LL. 


\section{A.2 Competition on the Entry Level}

As mentioned in the main text, firms have six potential hiring strategies. In addition to the two homogeneous configurations with high- or low-ability workers only (denoted HHHH and LLLL), there are four heterogeneous configurations in which a firm hires workers of both types: The firm may hire three high- and one low-ability worker (HHHL), or one high- and three low-ability workers (HLLL), or two workers of each type. In the latter case, the two separate entry level interactions could either be homogeneous (HHLL) or heterogeneous (HLHL). Subsequently, we will separately analyze the optimization problem of workers in each configuration.

Configuration HHHH. The optimization problem of worker $i$ in a promotion contest with four high-ability workers reads

$$
\max _{x_{i 1} \geq 0} \Pi_{i 1}\left(x_{i 1}, x_{j 1} \mid x_{k 1}, x_{l 1}\right)=\frac{x_{i 1}}{x_{i 1}+x_{j 1}}\left[s B+\Pi_{2}^{*}(\mathrm{H} \mid \mathrm{HH})\right]-\frac{x_{i 1}}{a_{\mathrm{H}}}
$$

i.e., worker $i$ initially competes against worker $j$ on the entry level by choosing the optimal effort $x_{i 1}$. The value of a promotion to the next stage equals $s B+\Pi_{2}^{*}(\mathrm{H} \mid \mathrm{HH})$, since the opponent on the intermediate level will always be a high-ability type. In the unique (symmetric) equilibrium, entry-level effort equals

$$
x_{\mathrm{H} 1}^{*} \equiv x_{i 1}^{*}=x_{j 1}^{*}=x_{k 1}^{*}=x_{l 1}^{*}=\frac{(1+2 s) a_{\mathrm{H}} B}{16} .
$$

Since entry-level effort is the same for all workers, each worker reaches the intermediate level with probability 0.5. Thus, total expected effort provision per worker across hierarchy levels equals

$$
x^{*}(\mathrm{H} \mid \mathrm{HHHH})=\underbrace{\frac{(1+2 s) a_{\mathrm{H}} B}{16}}_{x_{\mathrm{H} 1}^{*} \rightarrow \text { see }[.3]}+0.5 \cdot \underbrace{\frac{(1-2 s) a_{\mathrm{H}} B}{4}}_{x_{2}^{*}(\mathrm{H} \mid \mathrm{HH}) \rightarrow \text { see }[\text { A.1 }}
$$

Configuration HHHL. Assume that three high-ability workers $i, k$ and $l$ compete with lowability worker $j$, and that the two pairwise entry-level interactions are between workers $i$ and $j$, and between workers $k$ and $l$, respectively. Consider first workers $i$ and $j$ who anticipate that the ability of their intermediate-level opponent (conditional on receiving the initial promotion) is high, independent of entry-level efforts by $k$ and $l$. Therefore, the optimization problems of $i$ 
and $j$ read

$$
\begin{aligned}
& \max _{x_{i 1} \geq 0} \Pi_{i 1}\left(x_{i 1}, x_{j 1} \mid x_{k 1}, x_{l 1}\right)=\frac{x_{i 1}}{x_{i 1}+x_{j 1}}\left[s B+\Pi_{2}^{*}(\mathrm{H} \mid \mathrm{HH})\right]-\frac{x_{i 1}}{a_{\mathrm{H}}}, \\
& \max _{x_{j 1} \geq 0} \Pi_{j 1}\left(x_{j 1}, x_{i 1} \mid x_{k 1}, x_{l 1}\right)=\frac{x_{j 1}}{x_{i 1}+x_{j 1}}\left[s B+\Pi_{2}^{*}(\mathrm{~L} \mid \mathrm{HL})\right]-\frac{x_{j 1}}{a_{\mathrm{L}}} .
\end{aligned}
$$

Combining the first-order conditions of workers $i$ and $j$ delivers

$$
x_{i 1}^{*}=\frac{a_{\mathrm{H}}\left[s+\frac{a_{\mathrm{L}}^{2}(1-2 s)}{\left(a_{\mathrm{H}}+a_{\mathrm{L}}\right)^{2}}\right]\left[s+\frac{1-2 s}{4}\right]^{2} \cdot B}{\left[a_{\mathrm{L}}\left(s+\frac{a_{\mathrm{L}}^{2}(1-2 s)}{\left(a_{\mathrm{H}}+a_{\mathrm{L}}\right)^{2}}\right)+a_{\mathrm{H}}\left(s+\frac{1-2 s}{4}\right)\right]^{2}} \quad \text { and } \quad x_{j 1}^{*}=\frac{a_{\mathrm{L}}\left[s+\frac{a_{\mathrm{L}}^{2}(1-2 s)}{\left(a_{\mathrm{H}}+a_{\mathrm{L}}\right)^{2}}\right]^{2}\left[s+\frac{1-2 s}{4}\right] \cdot B}{\left[a_{\mathrm{L}}\left(s+\frac{a_{\mathrm{L}}^{2}(1-2 s)}{\left(a_{\mathrm{H}}+a_{\mathrm{L}}\right)^{2}}\right)+a_{\mathrm{H}}\left(s+\frac{1-2 s}{4}\right)\right]^{2}} \text {. }
$$

The optimization problems of workers $k$ and $l$ are symmetric. Both attach the value $s B+$ $p_{i}\left(x_{i 1}^{*}, x_{j 1}^{*}\right) \cdot \Pi_{2}^{*}(\mathrm{H} \mid \mathrm{HH})+\left[1-p_{i}\left(x_{i 1}^{*}, x_{j 1}^{*}\right)\right] \cdot \Pi_{2}^{*}(\mathrm{H} \mid \mathrm{HL})$ to the first promotion, where $p_{i}\left(x_{i 1}^{*}, x_{j 1}^{*}\right)$ is the probability that the high-ability worker $i$ outperforms the low-ability worker $j$ on the entry level. Entry-level equilibrium efforts for workers $k$ and $l$ are defined as

$$
x_{k 1}^{*}=x_{l 1}^{*}=\frac{a_{\mathrm{H}}}{4} \cdot\left[s+\frac{a_{\mathrm{L}}\left(s+\frac{a_{\mathrm{L}}^{2}(1-2 s)}{\left(a_{\mathrm{H}}+a_{\mathrm{L}}\right)^{2}}\right)\left(\frac{a_{\mathrm{H}}^{2}(1-2 s)}{\left(a_{\mathrm{H}}+a_{\mathrm{L}}\right)^{2}}\right)+a_{\mathrm{H}}\left(s+\frac{1-2 s}{4}\right)\left(\frac{1-2 s}{4}\right)}{a_{\mathrm{L}}\left(s+\frac{a_{\mathrm{L}}^{2}(1-2 s)}{\left(a_{\mathrm{H}}+a_{\mathrm{L}}\right)^{2}}\right)+a_{\mathrm{H}}\left(s+\frac{1-2 s}{4}\right)}\right] B .
$$

Using the above expressions for entry-level effort, as well as the the expressions for intermediatelevel effort in the relevant setting, provided in (A.1) and A.2), respectively, we can compute total expected effort provision across hierarchy levels for workers of each type. We start by considering the low-ability worker, who provides

$$
x^{*}(\mathrm{~L} \mid \mathrm{HHHL})=x_{j 1}^{*}+\frac{x_{j 1}^{*}}{x_{i 1}^{*}+x_{j 1}^{*}} \cdot x_{2}^{*}(\mathrm{LH})
$$

in expected terms. It is slightly more complicated to determine total expected effort by a highability worker, since the expected effort differs between workers $i$ and $k$ or $l$. Thus, we use the average total effort provision by a high-ability worker, which is defined as

$$
x^{*}(\mathrm{H} \mid \mathrm{HHHL})=\frac{1}{3}\left[x_{i 1}^{*}+x_{k 1}^{*}+x_{l 1}^{*}+2 \cdot \frac{x_{i 1}^{*}}{x_{i 1}^{*}+x_{j 1}^{*}} \cdot x_{2}^{*}(\mathrm{H} \mid \mathrm{HH})+\frac{x_{j 1}^{*}}{x_{i 1}^{*}+x_{j 1}^{*}} \cdot x_{2}^{*}(\mathrm{H} \mid \mathrm{HL})\right] .
$$

Configuration HHLL. Assume that the high-ability workers $i$ and $k$ participate in the same promotion contest as the low-ability workers $j$ and $l$. The two pairwise entry-level interactions are between workers $i$ and $k$, and between workers $j$ and $l$, respectively. Due to symmetry of the optimization problems, it suffices to solve the optimization problem of one high-ability $(i$ or 
$k$ ) and one low-ability worker $(j$ or $l$ ). Without loss of generality, we consider the maximization problems of workers $i$ and $j$,

$$
\begin{aligned}
& \max _{x_{i 1} \geq 0} \Pi_{i 1}\left(x_{i 1}, x_{k 1} \mid x_{j 1}, x_{l 1}\right)=\frac{x_{i 1}}{x_{i 1}+x_{k 1}}\left[s B+\Pi_{2}^{*}(\mathrm{H} \mid \mathrm{HL})\right]-\frac{x_{i 1}}{a_{\mathrm{H}}} \\
& \max _{x_{j 1} \geq 0} \Pi_{j 1}\left(x_{j 1}, x_{l 1} \mid x_{i 1}, x_{k 1}\right)=\frac{x_{j 1}}{x_{j 1}+x_{l 1}}\left[s B+\Pi_{2}^{*}(\mathrm{~L} \mid \mathrm{HL})\right]-\frac{x_{j 1}}{a_{\mathrm{L}}} .
\end{aligned}
$$

The optimization problem for high-ability workers is similar to the one we previously considered in the intermediate-level interaction $\mathrm{HH}$; the only difference is the prize, which now amounts to $s B+\Pi_{2}^{*}(\mathrm{H} \mid \mathrm{HL})$ rather than $B$. Analogously, low-ability workers face the same situation as in the intermediate-level interaction LL with a different prize. Consequently, first-order and symmetry conditions deliver entry-level equilibrium efforts

$$
\begin{aligned}
& x_{\mathrm{H} 1}^{*} \equiv x_{i 1}^{*}=x_{j 1}^{*}=\frac{a_{\mathrm{H}}\left[s\left(a_{\mathrm{H}}+a_{\mathrm{L}}\right)^{2}+a_{\mathrm{H}}^{2}(1-2 s)\right]}{4\left(a_{\mathrm{H}}+a_{\mathrm{L}}\right)^{2}} B \\
& x_{\mathrm{L} 1}^{*} \equiv x_{k 1}^{*}=x_{l 1}^{*}=\frac{a_{\mathrm{L}}\left[s\left(a_{\mathrm{H}}+a_{\mathrm{L}}\right)^{2}+a_{\mathrm{L}}^{2}(1-2 s)\right]}{4\left(a_{\mathrm{H}}+a_{\mathrm{L}}\right)^{2}} B .
\end{aligned}
$$

Since both interactions on the entry level are between workers of the same type, the probability of promotion to the intermediate level equals 0.5 for each worker, independent of her type. Therefore, total expected effort equals

$$
x^{*}(\mathrm{H} \mid \mathrm{HHLL})=\underbrace{\frac{a_{\mathrm{H}}\left[s\left(a_{\mathrm{H}}+a_{\mathrm{L}}\right)^{2}+a_{\mathrm{H}}^{2}(1-2 s)\right]}{4\left(a_{\mathrm{H}}+a_{\mathrm{L}}\right)^{2}}}_{x_{\mathrm{H} 1}^{*} \rightarrow \text { see }[\text { A.9] }} B+0.5 \cdot \underbrace{\frac{(1-2 s) a_{\mathrm{H}}^{2} a_{\mathrm{L}} B}{\left(a_{\mathrm{H}}+a_{\mathrm{L}}\right)^{2}}}_{x_{2}^{*}(\mathrm{H} \mid \mathrm{HL}) \rightarrow \text { see } \sqrt{\mathrm{A} .2}}
$$

for each high-ability worker, while each low-ability workers expects to provide

$$
x^{*}(\mathrm{~L} \mid \mathrm{HHLL})=\underbrace{\frac{a_{\mathrm{L}}\left[s\left(a_{\mathrm{H}}+a_{\mathrm{L}}\right)^{2}+a_{\mathrm{L}}^{2}(1-2 s)\right]}{4\left(a_{\mathrm{H}}+a_{\mathrm{L}}\right)^{2}}}_{x_{\mathrm{L} 1}^{*} \rightarrow \text { see } \sqrt{\mathrm{A} .10}}+0.5 \cdot \underbrace{\frac{(1-2 s) a_{\mathrm{H}} a_{\mathrm{L}}^{2} B}{\left(a_{\mathrm{H}}+a_{\mathrm{L}}\right)^{2}}}_{x_{2}^{*}(\mathrm{~L} \mid \mathrm{HL}) \rightarrow \text { see } \sqrt{\mathrm{A} .2}} .
$$

Configuration HLHL. Assume that the high-ability workers $i$ and $k$ participate in the same promotion contest as the low-ability workers $j$ and $l$. The two pairwise entry-level interactions are between workers $i$ and $j$, and between workers $k$ and $l$, respectively. We start by considering the decision problem of the high-ability worker $i$ and the low-ability worker $j$. Both workers choose their entry-level effort in such a way as to maximize the expected entry-level payoff $\Pi_{i 1}\left(x_{i 1}, x_{j 1} \mid x_{k 1}, x_{l 1}\right)$ and $\Pi_{j 1}\left(x_{j 1}, x_{i 1} \mid x_{l 1}, x_{k 1}\right)$, respectively, taking equilibrium behavior of other workers on the entry level and in any potential intermediate-level interaction as given. The 
optimization problems are

$$
\begin{aligned}
\max _{x_{i 1} \geq 0} \Pi_{i 1}\left(x_{i 1}, x_{j 1} \mid x_{k 1}, x_{l 1}\right) & =\frac{x_{i 1}}{x_{i 1}+x_{j 1}} \underbrace{\left[s B+\frac{x_{k 1}}{x_{k 1}+x_{l 1}} \Pi_{2}^{*}(\mathrm{H} \mid \mathrm{HH})+\frac{x_{l 1}}{x_{k 1}+x_{l 1}} \Pi_{2}^{*}(\mathrm{H} \mid \mathrm{HL})\right]}_{\equiv P_{i}\left(x_{k 1}, x_{l 1}\right)}-\frac{x_{i 1}}{a_{\mathrm{H}}} \\
\max _{x_{j 1} \geq 0} \Pi_{j 1}\left(x_{j 1}, x_{i 1} \mid x_{l 1}, x_{k 1}\right) & =\frac{x_{j 1}}{x_{i 1}+x_{j 1}} \underbrace{\left[s B+\frac{x_{k 1}}{x_{k 1}+x_{l 1}} \Pi_{2}^{*}(\mathrm{~L} \mid \mathrm{HL})+\frac{x_{l 1}}{x_{k 1}+x_{l 1}} \Pi_{2}^{*}(\mathrm{~L} \mid \mathrm{LL})\right]}_{\equiv P_{j}\left(x_{k 1}, x_{l 1}\right)}-\frac{x_{j 1}}{a_{\mathrm{L}}} .
\end{aligned}
$$

The continuation values $P_{i}\left(x_{k 1}, x_{l 1}\right)$ and $P_{j}\left(x_{k 1}, x_{l 1}\right)$ of workers $i$ and $j$, respectively, depend on the behavior of workers $k$ and $l$ in the parallel entry-level interaction. Similarly, the continuation values $P_{k}\left(x_{i 1}, x_{j 1}\right)$ and $P_{l}\left(x_{i 1}, x_{j 1}\right)$ of workers $k$ and $l$ depend on the behavior of workers $i$ and $j$. Therefore, the two entry-level interactions are linked through endogenously determined continuation values. The reason is that expected equilibrium payoffs for workers differ across the three potential intermediate-level interactions HH, LL, and HL. Conditional on receiving the first promotion, workers of both types have a higher expected payoff from meeting a low- rather than a high-ability opponent on the intermediate level, since $\Pi_{2}^{*}(\mathrm{~L} \mid \mathrm{LL})>\Pi_{2}^{*}(\mathrm{~L} \mid \mathrm{HL})$ and $\Pi_{2}^{*}(\mathrm{H} \mid \mathrm{HL})>$ $\Pi_{2}^{*}(\mathrm{H} \mid \mathrm{HH})$. However, each worker takes the probability that the opponent is of a certain type as given, since it is determined in the parallel entry-level interaction. The first-order conditions for the interaction between $i$ and $j$ read

$$
a_{\mathrm{H}} x_{j 1} P_{i}\left(x_{k 1}, x_{l 1}\right)-\left(x_{i 1}+x_{j 1}\right)^{2}=0 \quad \text { and } \quad a_{\mathrm{L}} x_{i 1} P_{k}\left(x_{k 1}, x_{l 1}\right)-\left(x_{i 1}+x_{j 1}\right)^{2}=0 .
$$

Combining these conditions, as well as the respective conditions for the second entry-level interaction between workers $k$ and $l$, we obtain two expressions that define a relation between equilibrium effort choices of workers within each interaction, namely

$$
\frac{x_{i 1}}{x_{j 1}}=\frac{a_{\mathrm{H}}}{a_{\mathrm{L}}} \frac{P_{i}\left(x_{k 1}, x_{l 1}\right)}{P_{j}\left(x_{k 1}, x_{l 1}\right)} \quad \text { and } \quad \frac{x_{k 1}}{x_{l 1}}=\frac{a_{\mathrm{H}}}{a_{\mathrm{L}}} \frac{P_{k}\left(x_{i 1}, x_{j 1}\right)}{P_{l}\left(x_{i 1}, x_{j 1}\right)}
$$

These expressions show that each entry-level interaction is a contest between workers with different ability and endogenously different valuations of winning. While the ability differs by assumption, the difference of the value for winning is a result of the contest structure: Reaching the intermediate value is more valuable for high- than for low-ability workers.

We proceed now to the solution of the problem, which comprises two heterogeneous participants with regard to their ability and their valuation. As mentioned previously, any contest with two heterogeneous participants has a unique, interior equilibrium for the chosen contest 
success function (Cornes and Hartley 2005, Nti 1999). Consequently, each of the two pairwise entry-level interactions has a unique equilibrium for each pair of continuation values. What remains to be shown is that the two expressions in A.13 can be satisfied jointly such that FOCs in both entry-level interactions are satisfied simultaneously in equilibrium. Imposing symmetry $\left(x_{\mathrm{H} 1}^{*} \equiv x_{i 1}^{*}=x_{k 1}^{*}, x_{\mathrm{L} 1}^{*} \equiv x_{j 1}^{*}=x_{l 1}^{*}\right)$, inserting the continuation values in (A.13), and simplifying gives

$$
\frac{x_{\mathrm{H} 1}^{*}}{x_{\mathrm{L} 1}^{*}}=\underbrace{\frac{\left(a_{\mathrm{H}}-a_{\mathrm{L}}\right)\left(a_{\mathrm{H}}+a_{\mathrm{L}}\right)^{2}(1+2 s)+\sqrt{\phi\left(s, a_{\mathrm{H}}, a_{\mathrm{L}}\right)}}{8 a_{\mathrm{L}}\left[a_{\mathrm{L}}^{2}+s\left(a_{\mathrm{H}}^{2}+2 a_{\mathrm{H}} a_{\mathrm{H}}-a_{\mathrm{L}}^{2}\right)\right]}}_{\equiv F^{*}\left(s, a_{\mathrm{H}}, a_{\mathrm{L}}\right)} .
$$

where $\phi(\cdot)=64 a_{\mathrm{H}} a_{\mathrm{L}}\left[a_{\mathrm{H}}^{2}+s\left(a_{\mathrm{L}}^{2}+2 a_{\mathrm{H}} a_{\mathrm{L}}-a_{\mathrm{H}}^{2}\right)\right] \cdot\left[a_{\mathrm{L}}^{2}+s\left(a_{\mathrm{H}}^{2}+2 a_{\mathrm{H}} a_{\mathrm{L}}-a_{\mathrm{L}}^{2}\right)\right]+\left(a_{\mathrm{H}}-a_{\mathrm{L}}\right)^{2}\left(a_{\mathrm{H}}+a_{\mathrm{L}}\right)^{4}(1+2 s)$. $F^{*}\left(s, a_{\mathrm{H}}, a_{\mathrm{L}}\right)$ defines the unique ratio of (positive) equilibrium efforts which ensures that effort choices are mutually optimal within and across the two entry-level interactions. Inserting $\frac{x_{\mathrm{H} 1}^{*}}{x_{\mathrm{L} 1}^{*}}$ from A.14 in the first-order optimality conditions gives entry-level equilibrium efforts

$$
\begin{aligned}
& x_{\mathrm{H} 1}^{*} \equiv x_{i 1}^{*}=x_{k 1}^{*}=\frac{a_{\mathrm{H}}\left(a_{\mathrm{H}}+a_{\mathrm{L}}\right)^{2} F^{*}\left(s, a_{\mathrm{H}}, a_{\mathrm{L}}\right)^{2}+4 a_{\mathrm{H}}^{3} F^{*}\left(s, a_{\mathrm{H}}, a_{\mathrm{L}}\right)}{4\left(a_{\mathrm{H}}+a_{\mathrm{L}}\right)^{2}\left[1+F^{*}\left(s, a_{\mathrm{H}}, a_{\mathrm{L}}\right)\right]^{3}}, \\
& x_{\mathrm{L} 1}^{*} \equiv x_{j 1}^{*}=x_{l 1}^{*}=\frac{a_{\mathrm{L}}\left(a_{\mathrm{H}}+a_{\mathrm{L}}\right)^{2} F^{*}\left(s, a_{\mathrm{H}}, a_{\mathrm{L}}\right)+4 a_{\mathrm{L}}^{3} F^{*}\left(s, a_{\mathrm{H}}, a_{\mathrm{L}}\right)^{2}}{4\left(a_{\mathrm{H}}+a_{\mathrm{L}}\right)^{2}\left[1+F^{*}\left(s, a_{\mathrm{H}}, a_{\mathrm{L}}\right)\right]^{3}} .
\end{aligned}
$$

Using the formal expressions for equilibrium effort on the entry level, provided in A.15) and A.16 above, as well as the expressions for intermediate-level effort in the respective setting, provided in A.1 and A.2, respectively, we can compute total expected effort provision for workers of each type: Each high-ability worker provides

$$
x^{*}(\mathrm{H} \mid \mathrm{HLHL})=x_{\mathrm{H} 1}^{*}+\frac{x_{\mathrm{H} 1}^{*}}{x_{\mathrm{H} 1}^{*}+x_{\mathrm{L} 1}^{*}}\left[\frac{x_{\mathrm{H} 1}^{*}}{x_{\mathrm{H} 1}^{*}+x_{\mathrm{L} 1}^{*}} \cdot x_{2}^{*}(\mathrm{H} \mid \mathrm{HH})+\frac{x_{\mathrm{L} 1}^{*}}{x_{\mathrm{H} 1}^{*}+x_{\mathrm{L} 1}^{*}} \cdot x_{2}^{*}(\mathrm{H} \mid \mathrm{HL})\right]
$$

in expected terms, while the expected total effort by each low-ability worker amounts to

$$
x^{*}(\mathrm{~L} \mid \mathrm{HLHL})=x_{\mathrm{L} 1}^{*}+\frac{x_{\mathrm{L} 1}^{*}}{x_{\mathrm{H} 1}^{*}+x_{\mathrm{L} 1}^{*}}\left[\frac{x_{\mathrm{L} 1}^{*}}{x_{\mathrm{H} 1}^{*}+x_{\mathrm{L} 1}^{*}} \cdot x_{2}^{*}(\mathrm{~L} \mid \mathrm{LL})+\frac{x_{\mathrm{H} 1}^{*}}{x_{\mathrm{H} 1}^{*}+x_{\mathrm{L} 1}^{*}} \cdot x_{2}^{*}(\mathrm{~L} \mid \mathrm{HL})\right] .
$$

Configuration HLLL. Assume that three low-ability workers $i, k$ and $l$ compete with the highability worker $j$ in a promotion contest.The two pairwise entry-level interactions are between workers $i$ and $j$, and between workers $k$ and $l$, respectively. Consider first workers $i$ and $j$ who anticipate that the ability of their intermediate-level opponent (conditional on receiving the initial promotion) is low, independent of entry-level efforts by $k$ and $l$. Therefore, the 
optimization problems of $i$ and $j$ read

$$
\begin{aligned}
& \max _{x_{i 1} \geq 0} \Pi_{i 1}\left(x_{i 1}, x_{j 1} \mid x_{k 1}, x_{l 1}\right)=\frac{x_{i 1}}{x_{i 1}+x_{j 1}}\left[s B+\Pi_{2}^{*}(\mathrm{~L} \mid \mathrm{LL})\right]-\frac{x_{i 1}}{a_{\mathrm{L}}}, \\
& \max _{x_{j 1} \geq 0} \Pi_{j 1}\left(x_{j 1}, x_{i 1} \mid x_{k 1}, x_{l 1}\right)=\frac{x_{j 1}}{x_{i 1}+x_{j 1}}\left[s B+\Pi_{2}^{*}(\mathrm{H} \mid \mathrm{HL})\right]-\frac{x_{j 1}}{a_{\mathrm{H}}} .
\end{aligned}
$$

Combining the first-order conditions of workers $i$ and $j$ delivers

$$
x_{i 1}^{*}=\frac{a_{\mathrm{L}}\left[s+\frac{c_{\mathrm{H}}^{2}(1-2 s)}{\left(a_{\mathrm{H}}+a_{\mathrm{L}}\right)^{2}}\right]\left[s+\frac{1-2 s}{4}\right]^{2} \cdot B}{\left[a_{\mathrm{H}}\left(s+\frac{a_{\mathrm{H}}^{2}(1-2 s)}{\left(a_{\mathrm{H}}+a_{\mathrm{L}}\right)^{2}}\right)+a_{\mathrm{L}}\left(s+\frac{1-2 s}{4}\right)\right]^{2}} \quad \text { and } \quad x_{j 1}^{*}=\frac{a_{\mathrm{H}}\left[s+\frac{a_{\mathrm{H}}^{2}(1-2 s)}{\left(a_{\mathrm{H}}+a_{\mathrm{L}}\right)^{2}}\right]^{2}\left[s+\frac{1-2 s}{4}\right] \cdot B}{\left[a_{\mathrm{H}}\left(s+\frac{a_{\mathrm{H}}^{2}(1-2 s)}{\left(a_{\mathrm{H}}+a_{\mathrm{L}}\right)^{2}}\right)+a_{\mathrm{L}}\left(s+\frac{1-2 s}{4}\right)\right]^{2}} .
$$

The optimization problems of workers $k$ and $l$ are symmetric. Both attach the value $s B+$ $p_{i}\left(x_{i 1}^{*}, x_{j 1}^{*}\right) \cdot \Pi_{2}^{*}(\mathrm{~L} \mid \mathrm{LL})+\left[1-p_{i}\left(x_{i 1}^{*}, x_{j 1}^{*}\right)\right] \cdot \Pi_{2}^{*}(\mathrm{~L} \mid \mathrm{HL})$ to the $1^{\text {st }}$ promotion possibility, where $p_{i}\left(x_{i 1}^{*}, x_{j 1}^{*}\right)$ is the probability that the low-ability worker $i$ wins the entry-level interaction against the highability worker $j$; entry-level equilibrium efforts for workers $k$ and $l$ are defined as

$$
x_{k 1}^{*}=x_{l 1}^{*}=\frac{a_{\mathrm{L}}}{4} \cdot\left[s+\frac{a_{\mathrm{H}}\left(s+\frac{a_{\mathrm{H}}^{2}(1-2 s)}{\left(a_{\mathrm{H}}+a_{\mathrm{L}}\right)^{2}}\right)\left(\frac{a_{\mathrm{L}}^{2}(1-2 s)}{\left(a_{\mathrm{H}}+a_{\mathrm{L}}\right)^{2}}\right)+a_{\mathrm{L}}\left(s+\frac{a_{\mathrm{L}}^{2}(1-2 s)}{\left(a_{\mathrm{H}}+a_{\mathrm{L}}\right)^{2}}\right)\left(\frac{1-2 s}{4}\right)}{a_{\mathrm{H}}\left(s+\frac{a_{\mathrm{H}}^{2}(1-2 s)}{\left(a_{\mathrm{H}}+a_{\mathrm{L}}\right)^{2}}\right)+a_{\mathrm{L}}\left(s+\frac{1-2 s}{4}\right)}\right] B .
$$

Using the above expressions for entry-level effort, as well as the the expressions for intermediatelevel effort in the relevant setting, provided in (A.1) and A.2), respectively, we can compute total expected effort provision for workers of each type. We start by considering the high-ability worker, who provides

$$
x^{*}(\mathrm{H} \mid \mathrm{HLLL})=x_{j 1}^{*}+\frac{x_{j 1}^{*}}{x_{i 1}^{*}+x_{j 1}^{*}} \cdot x_{2}^{*}(\mathrm{H} \mid \mathrm{HL})
$$

in expected terms. It is slightly more complicated to determine total expected effort by a lowability worker, since the expected effort differs between workers $i$ and $k$ or $l$. Thus, we use the average total effort provision by a low-ability worker, which is defined as

$$
x^{*}(\mathrm{~L} \mid \mathrm{HLLL})=\frac{1}{3}\left[x_{i 1}^{*}+x_{k 1}^{*}+x_{l 1}^{*}+2 \cdot \frac{x_{i 1}^{*}}{x_{i 1}^{*}+x_{j 1}^{*}} \cdot x_{2}^{*}(\mathrm{~L} \mid \mathrm{LL})+\frac{x_{j 1}^{*}}{x_{i 1}^{*}+x_{j 1}^{*}} \cdot x_{2}^{*}(\mathrm{~L} \mid \mathrm{HL})\right] .
$$

Setting LLLL. The optimization problem of worker $i$ in a promotion contest with four lowability workers reads

$$
\max _{x_{i 1} \geq 0} \Pi_{i 1}\left(x_{i 1}, x_{j 1} \mid x_{k 1}, x_{l 1}\right)=\frac{x_{i 1}}{x_{i 1}+x_{j 1}}\left[s+\Pi_{2}^{*}(\mathrm{~L} \mid \mathrm{LL})\right]-\frac{x_{i 1}}{a_{\mathrm{L}}},
$$


i.e., worker $i$ initially competes against worker $j$ on the entry level by choosing the optimal effort $x_{i 1}$. The value of a promotion to the next hierarchy level equals $s+\Pi_{2}^{*}(\mathrm{~L} \mid \mathrm{LL})$, since the opponent on the intermediate level will always be a low-ability type. In the unique (symmetric) equilibrium, entry level effort equals

$$
x_{\mathrm{L} 1}^{*} \equiv x_{i 1}^{*}=x_{j 1}^{*}=x_{k 1}^{*}=x_{l 1}^{*}=\frac{(1+2 s) a_{\mathrm{L}} B}{16} .
$$

Since entry-level effort is the same for all workers, each worker reaches the intermediate level with probability 0.5 . Thus, total expected effort provision per worker across hierarchy levels equals

$$
x^{*}(\mathrm{LLLL})=\underbrace{\frac{(1+2 s) a_{\mathrm{L}} B}{16}}_{x_{\mathrm{L} 1}^{*} \rightarrow \text { see }[\mathrm{A.23]}}+0.5 \cdot \underbrace{\frac{(1-2 s) a_{\mathrm{L}} B}{4}}_{x_{2}^{*}(\mathrm{~L} \mid \mathrm{LL}) \rightarrow \text { see }[\mathrm{A.1}}
$$

\section{B Proofs}

Proof of Proposition 1 Equilibrium effort choices for high- and low-ability workers in homogeneous and heterogeneous intermediate-level interactions are provided in Table 1. Consider high-ability workers first. We have to show that the relation

$$
x_{2}^{*}(\mathrm{H} \mid \mathrm{HL})-x_{2}^{*}(\mathrm{H} \mid \mathrm{HH})<0
$$

is satisfied for all values of $a_{\mathrm{H}}, a_{\mathrm{L}}$, and $0 \leq s<1$. Inserting the formal expressions delivers

$$
\begin{aligned}
\frac{a_{\mathrm{H}}^{2} a_{\mathrm{L}}(1-2 s) B}{\left(a_{\mathrm{H}}+a_{\mathrm{L}}\right)^{2}} & <\frac{a_{\mathrm{H}}(1-2 s) B}{4} \\
\Leftrightarrow 4 a_{\mathrm{H}}^{2} a_{\mathrm{L}} & <a_{\mathrm{H}}^{3}+2 a_{\mathrm{H}}^{2} a_{\mathrm{L}}+a_{\mathrm{H}} a_{\mathrm{L}}^{2} \\
\Leftrightarrow 0 & <a_{\mathrm{H}}\left(a_{\mathrm{H}}-a_{\mathrm{L}}\right)^{2}
\end{aligned}
$$

which proves that the incentive effect of heterogeneity is strictly negative for high-ability workers on the intermediate level. Consider low-ability workers next. We have to show that the relation

$$
x_{2}^{*}(\mathrm{~L} \mid \mathrm{HL})-x_{2}^{*}(\mathrm{~L} \mid \mathrm{LL})<0
$$


is satisfied for all values of $a_{\mathrm{H}}, a_{\mathrm{L}}$, and $0 \leq s<1$. Inserting the formal expressions delivers

$$
\begin{aligned}
\frac{a_{\mathrm{H}} a_{\mathrm{L}}^{2}(1-2 s) B}{\left(a_{\mathrm{H}}+a_{\mathrm{L}}\right)^{2}} & <\frac{a_{\mathrm{L}}(1-2 s) B}{4} \\
\Leftrightarrow 4 a_{\mathrm{H}} a_{\mathrm{L}}^{2} & <a_{\mathrm{L}}^{3}+2 a_{\mathrm{H}} a_{\mathrm{L}}^{2}+a_{\mathrm{H}}^{2} a_{\mathrm{L}} \\
\Leftrightarrow 0 & <a_{\mathrm{L}}\left(a_{\mathrm{H}}-a_{\mathrm{L}}\right)^{2}
\end{aligned}
$$

which proves that the incentive effect of heterogeneity is strictly negative for high-ability workers on the intermediate level.

Proof of Proposition 2 According to Result 2, the incentive effect of heterogeneity on the entry level is always negative for low-ability workers, but may turn out to be positive for highability types. To prove this claim, consider the optimization problem of a worker on the entry level:

$$
\max _{x_{11} \geq 0} \Pi_{11}\left(x_{11}, x_{21} \mid x_{31}, x_{41}\right)=\frac{x_{11}}{x_{11}+x_{21}}\left[s B+\mathrm{CV}_{1}\left(x_{31}, x_{41}\right)\right]-\frac{x_{11}}{a_{m}}
$$

where the continuation value $\mathrm{CV}_{1}\left(x_{31}, x_{41}\right)$ is defined as follows:

$$
\mathrm{CV}_{1}\left(x_{31}, x_{41}\right)=\frac{x_{31}}{x_{31}+x_{41}} \Pi_{12}\left(x_{12}^{*}, x_{32}^{*}\right)+\frac{x_{41}}{x_{31}+x_{41}} \Pi_{12}\left(x_{12}^{*}, x_{42}^{*}\right)
$$

The effort choice of worker 1 is potentially affected by two difference sources of heterogeneity. First, the entry-level interaction is heterogeneous when the ability of workers 1 and 2 differs. We know from Result 1 that this 'within-interaction' effect of heterogeneity is strictly negative both for high- and low-ability workers. Second, the ability of workers 3 and 4 who compete in the parallel entry-level interaction can be different. In this case, the continuation value of worker 1 changes, which affects the effort choice of worker 1 for any given degree of "withininteraction' heterogeneity. The 'continuation-value' effect due to heterogeneity in the parallel entry-level interaction is positive for high-ability workers (since $\Pi_{2}(\mathrm{H} \mid \mathrm{HL})>\Pi_{2}(\mathrm{H} \mid \mathrm{HH})$ ), and negative for low-ability workers (since $\Pi_{2}(\mathrm{~L} \mid \mathrm{HL})<\Pi_{2}(\mathrm{~L} \mid \mathrm{LL})$ ). Thus, both incentive effects of heterogeneity on the entry level work in the same direction and are strictly negative for lowability workers, which implies that the joint effect is necessarily negative. In contrast, the joint effect of heterogeneity on incentives on the entry-level is determined by two countervailing effects for high-ability workers.

Proof of Proposition 3 According to Result 3 , the incentive effect of heterogeneity across both levels is always negative for low-ability workers, but may turn out to be positive for high- 
ability types. Consider low-ability workers first: We already know from Results 1 and 2 that heterogeneity reduces incentives of low-ability workers both on the entry and on the intermediate level. The only additional effect that matters for the effect across both levels is the selection effect, which cannot be positive for workers of this type. This implies that the incentive effect of heterogeneity across both levels is always negative for low-ability workers. Next, consider high-ability workers. According to Results 1 and 2 , heterogeneity on the intermediate level unambiguously reduces incentives of high-ability workers, whereas two countervailing heterogeneity effects affect incentives on the entry level. The only additional factor that comes into play when considering the effect across both levels is the selection effect. This effect is necessarily non-negative for high-ability workers, since the equilibrium winning probability of any worker is decreasing in the ability of the opponent.

Proof of Lemma 1 We must prove that the relation $\Delta x_{1}^{*}(\mathrm{HHLL}):=2 \cdot \Delta x_{1}^{*}(\mathrm{H} \mid \mathrm{HHLL})+2$. $\Delta x_{1}^{*}(\mathrm{~L} \mid \mathrm{HHLL})>0$ is satisfied for all $0 \leq s<0.5$ and $0<a_{\mathrm{L}}<a_{\mathrm{H}}$. Inserting the respective equilibrium-effort choices and rearranging delivers

$$
\begin{aligned}
4\left(a_{\mathrm{H}}^{3}+a_{\mathrm{L}}^{3}\right)(1-2 s)-\left(a_{\mathrm{H}}+a_{\mathrm{L}}\right)^{3}(1-2 s) & >0 \\
\Leftrightarrow 4\left(a_{\mathrm{H}}^{3}+a_{\mathrm{L}}^{3}\right)-\left(a_{\mathrm{H}}+a_{\mathrm{L}}\right)^{3} & >0 \\
\Leftrightarrow 3\left(a_{\mathrm{H}}-a_{\mathrm{L}}\right)^{2}\left(a_{\mathrm{H}}+a_{\mathrm{L}}\right) & >0
\end{aligned}
$$

which proves Lemma 1

Proof of Lemma 2 We must prove that the relation

$$
z \cdot\left[p\left(\mathrm{H} \mid C^{h e t}\right)-0.5\right] \cdot x_{2}^{*}(\mathrm{H} \mid \mathrm{HH})+(4-z) \cdot\left[p\left(\mathrm{~L} \mid C^{h e t}\right)-0.5\right] \cdot x_{2}^{*}(\mathrm{~L} \mid \mathrm{LL}) \geq 0
$$

is satisfied for any $C^{\text {het }} \in\{$ HLLL , HHLL , HLHL , HHHL $\}$, all $0 \leq s<0.5$ and $0<a_{\mathrm{L}}<a_{\mathrm{H}}$. First, the probability of a promotion to the intermediate level for any high- or low-ability worker is the same in homogeneous and heterogeneous configurations whenever the workers of the same type compete on the entry level - as in both entry-level interactions of configuration HHLL, and in the homogeneous entry-level interaction of configurations HLLL and HHHL. In these cases, the selection effect is exactly zero. Next, consider all heterogeneous entry-level interactions. In particular, one of the two entry-level interactions is between different worker types in configuration HLLL and HHHL, while both entry-level interactions are heterogeneous in configuration HLHL. The 
probability to reach the intermediate level must sum up to one in each heterogeneous interaction. Thus, the probability gain due to heterogeneity for high-ability workers is exactly offset by the probability loss of the low-ability worker. Since the intermediate-level effort is strictly higher for high- than for low-ability workers, i.e. $x_{2}^{*}(\mathrm{H} \mid \mathrm{HH})>x_{2}^{*}(\mathrm{~L} \mid \mathrm{LL})$. Consequently, total effort provision by all workers increases as the probability for a promotion to the intermediate level increases for high-ability workers.

Proof of Proposition 4 We must prove that expected profits of a deviating firm $d$ that employs workers of different types are strictly higher than the profits $\tilde{\Psi}$ of firms with a homogeneous workforce in at least one heterogeneous configuration. We subsequently consider the heterogeneous configuration HHLL which delivers the simplest expressions for equilibrium-effort choices of workers. Thus, the claim that at least one heterogeneous configuration of types exists in which profits are higher than in case of homogeneity is proven if we can establish that the relation $\Psi($ HHLL $)>\tilde{\Psi}$ holds for all $0 \leq s<0.5$ and $0<a_{\mathrm{L}}<a_{\mathrm{H}}$. From (9) we know that the difference in profits is determined by the aggregate incentive effect of heterogeneity across highand low-ability workers for given fixed wages $\left\{\omega_{\mathrm{L}}^{*}, \omega_{\mathrm{H}}^{*}\right\}$. Therefore, we must show that

$$
\Leftrightarrow V\{2 \underbrace{\left[x^{*}(\mathrm{H} \mid \mathrm{HHLL})-x^{*}(\mathrm{H} \mid \mathrm{HHHH})\right]}_{\text {incentive effect high-ability }}+2 \underbrace{\left[x^{*}(\mathrm{~L} \mid \mathrm{HHLL})-x^{*}(\mathrm{~L} \mid \mathrm{LLLL})\right]}_{\text {incentive effect low-ability }}\}>0
$$

is satisfied for all $0 \leq s<0.5$ and $0<a_{\mathrm{L}}<a_{\mathrm{H}}$. It is a sufficient condition for B.1 to show that the following relation is always satisfied:

$$
\begin{aligned}
x^{*}(\mathrm{H} \mid \mathrm{HHLL})-x^{*}(\mathrm{H} \mid \mathrm{HHHH})+x^{*}(\mathrm{~L} \mid \text { HHLL })-x^{*}(\mathrm{~L} \mid \mathrm{LLLL}) & >0 \\
\Leftrightarrow \frac{a_{\mathrm{H}}\left(a_{\mathrm{H}}-a_{\mathrm{L}}\right)\left(3 a_{\mathrm{L}}+a_{\mathrm{H}}\right)(1-2 s)}{16\left(a_{\mathrm{H}}+a_{\mathrm{L}}\right)^{2}}-\frac{a_{\mathrm{L}}\left(a_{\mathrm{H}}-a_{\mathrm{L}}\right)\left(a_{\mathrm{L}}+3 a_{\mathrm{H}}\right)(1-2 s)}{16\left(a_{\mathrm{H}}+a_{\mathrm{L}}\right)^{2}} & >0 \\
\Leftrightarrow \frac{\left(a_{\mathrm{H}}-a_{\mathrm{L}}\right)^{2}(1-2 s)}{16\left(a_{\mathrm{H}}+a_{\mathrm{L}}\right)} & >0
\end{aligned}
$$

which completes the proof, since $0 \leq s<0.5$ and $0<a_{\mathrm{L}}<a_{\mathrm{H}}$ by assumption.

Proof of Proposition 5 We know from the proof of Proposition 4 that $\Psi($ HHLL $)>\tilde{\Psi}$ holds for all $0 \leq s<0.5$ and $0<a_{\mathrm{L}}<a_{\mathrm{H}}$. Therefore, it is sufficient for the proof of Proposition 5 to show that the expected payoff gain for high-ability workers in configuration HHLL exceeds the corresponding expected payoff loss for low-ability workers in this configuration relative to the 
homogeneous benchmark. Formally, we must show that the relation

$$
\underbrace{\Pi_{\mathrm{H} 1}(\mathrm{HHLL})-\Pi_{\mathrm{H} 1}(\mathrm{HHHH})}_{\text {payoff change of each high-ability worker }}+\underbrace{\Pi_{\mathrm{L} 1}(\mathrm{HHLL})-\Pi_{\mathrm{L} 1}(\mathrm{LLLL})}_{\text {payoff change of each low-ability worker }}>0
$$

is satisfied for $0 \leq s<0.5$ and $0<a_{\mathrm{L}}<a_{\mathrm{H}}$. When inserting the respective equilibrium values, we obtain

$$
\begin{aligned}
& \frac{\left(a_{\mathrm{H}}^{2}+a_{\mathrm{L}}^{2}\right)(1-2 s)}{\left(a_{\mathrm{H}}+a_{\mathrm{L}}\right)^{2}}>\frac{1-2 s}{2} \\
& \Leftrightarrow \quad 2\left(a_{\mathrm{H}}^{2}+a_{\mathrm{L}}^{2}\right)>\left(a_{\mathrm{H}}+a_{\mathrm{L}}\right)^{2} \\
& \Leftrightarrow \quad\left(a_{\mathrm{H}}-a_{\mathrm{L}}\right)^{2}>0
\end{aligned}
$$

which proves the claim that the gain due to heterogeneity for high-ability workers exceeds the corresponding loss for low-ability workers. Consequently, it is possible to modify fixed wages of high- and low-ability workers in such a way that workers of either type are better of in the heterogeneous configuration HHLL than in case of homogeneity.

\section{Generalized Monitoring Technology}

Consider a generalized Tullock (1980) contest with

$$
p_{i}\left(x_{i}, x_{j}\right)=\left\{\begin{array}{ccc}
\frac{x_{i}^{r}}{x_{i}^{r}+x_{j}^{r}} & \text { if } & x_{i}^{r}+x_{j}^{r}>0 \\
\frac{1}{2} & \text { if } & x_{i}^{r}+x_{j}^{r}=0
\end{array} .\right.
$$

where the parameter $r$ measures the precision of the monitoring technology; (ordinal) monitoring is imprecise for low values of $r$, and perfectly precise for $r \rightarrow \infty$. In this case, the optimization problems of high- and low-ability workers on the intermediate level of configuration HHLL reads as follows:

$$
\begin{aligned}
& \max _{x_{\mathrm{H} 2} \geq 0} \Pi_{\mathrm{H}}\left(x_{\mathrm{H} 2}, x_{\mathrm{L} 2}\right)=\frac{x_{\mathrm{H} 2}^{r}}{x_{\mathrm{H} 2}^{r}+x_{\mathrm{L} 2}^{r}}(1-2 s) B-\frac{x_{\mathrm{H} 2}}{a_{\mathrm{H}}}, \\
& \max _{x_{\mathrm{L} 2} \geq 0} \Pi_{\mathrm{L}}\left(x_{\mathrm{L} 2}, x_{\mathrm{H} 2}\right)=\frac{x_{\mathrm{L} 2}^{r}}{x_{\mathrm{H} 2}^{r}+x_{\mathrm{L} 2}^{r}}(1-2 s) B-\frac{x_{\mathrm{L} 2}}{a_{\mathrm{L}}} .
\end{aligned}
$$

First order conditions are necessary and sufficient if and only if $0<r<1+\left(\frac{a_{\mathrm{L}}}{a_{\mathrm{H}}}\right)^{r}$, as shown by Nti (1999); intuitively, the expected equilibrium payoff for the low-ability worker becomes 
negative if the condition is violated, and an equilibrium in pure strategies does no longer exist. We restrict attention to pure strategy equilibria subsequently.21 The combination of first-order conditions delivers Nash equilibrium intermediate-level efforts

$$
x_{\mathrm{H} 2}^{*}=\frac{r a_{\mathrm{H}}\left(\frac{a_{\mathrm{H}}}{a_{\mathrm{L}}}\right)^{r}(1-2 s) B}{\left[1+\left(\frac{a_{\mathrm{H}}}{a_{\mathrm{L}}}\right)^{r}\right]^{2}} \quad \text { and } \quad x_{\mathrm{L} 2}^{*}=\frac{r a_{\mathrm{L}}\left(\frac{a_{\mathrm{H}}}{a_{\mathrm{L}}}\right)^{r}(1-2 s) B}{\left[1+\left(\frac{a_{\mathrm{H}}}{a_{\mathrm{L}}}\right)^{r}\right]^{2}} \text {. }
$$

Inserting optimal actions in the two objective functions gives the expected equilibrium payoffs

$$
\Pi_{\mathrm{H}}^{*}(\cdot)=\frac{\left(\frac{a_{\mathrm{H}}}{a_{\mathrm{L}}}\right)^{2 r}+(1-r)\left(\frac{a_{\mathrm{H}}}{a_{\mathrm{L}}}\right)^{r}}{\left[1+\left(\frac{a_{\mathrm{H}}}{a_{\mathrm{L}}}\right)^{r}\right]^{2}}(1-2 s) B \quad \text { and } \quad \Pi_{\mathrm{L}}^{*}(\cdot)=\frac{1+(1-r)\left(\frac{a_{\mathrm{H}}}{a_{\mathrm{L}}}\right)^{r}}{\left[1+\left(\frac{a_{\mathrm{H}}}{a_{\mathrm{L}}}\right)^{r}\right]^{2}}(1-2 s) B
$$

Workers on the entry-level, high- and low-ability workers compete in two homogeneous interactions for a promotion to the intermediate level. Equilibrium efforts on the entry level read

$$
x_{\mathrm{H} 1}^{*}=r\left(\frac{a_{\mathrm{H}}}{4}\right)\left[s B+\Pi_{\mathrm{H}}^{*}\left(x_{\mathrm{H} 2}^{*}, x_{\mathrm{L} 2}^{*}\right)\right] \quad \text { and } \quad x_{\mathrm{L} 1}^{*}=r\left(\frac{a_{\mathrm{L}}}{4}\right)\left[s B+\Pi_{\mathrm{L}}^{*}\left(x_{\mathrm{L} 2}^{*}, x_{\mathrm{H} 2}^{*}\right)\right] \text {. }
$$

Equations (C.1), C.2 , and (C.3) define total expected effort provision by each high- and lowability worker in configuration HHLL as

$$
x^{*}(\mathrm{H} \mid \mathrm{HHLL})=x_{\mathrm{H} 1}^{*}+0.5 \cdot x_{\mathrm{H} 2}^{*} \quad \text { and } \quad x^{*}(\mathrm{~L} \mid \mathrm{HHLL})=x_{\mathrm{L} 1}^{*}+0.5 \cdot x_{\mathrm{L} 2}^{*},
$$

respectively. To determine the aggregate incentive effect of heterogeneity across workers, we need the equilibrium effort in homogeneous configurations HHHH and LLLL. However, assuming $a_{\mathrm{H}}=a_{\mathrm{L}}$, or $a_{\mathrm{L}}=a_{\mathrm{H}}$ delivers the respective expressions. What remains to be shown in that

$$
\Psi(\mathrm{HHLL})=2 V *\{\underbrace{\left[x^{*}(\mathrm{H} \mid \mathrm{HHLL})-x^{*}(\mathrm{H} \mid \mathrm{HHHH})\right]}_{\text {incentive effect for high-ability }}+\underbrace{\left[x^{*}(\mathrm{~L} \mid \mathrm{HHLL})-x^{*}(\mathrm{~L} \mid \mathrm{LLLL})\right]}_{\text {incentive effect for low-ability }}\}>0 .
$$

also holds for the generalized monitoring technology. Inserting the respective formal expressions and normalizing $a_{\mathrm{L}}=1$ delivers the condition

$$
r \frac{\left(a_{\mathrm{H}}^{r}-1\right)\left(4 a_{\mathrm{H}}-r-a_{\mathrm{H}} r+a_{\mathrm{H}}^{r}\left(-4+r+a_{\mathrm{H}} r\right)\right)(2 s-1)}{16 a_{\mathrm{H}}\left(1+a_{\mathrm{H}}^{r}\right)^{2}}>0 .
$$

${ }^{21}$ Little is known about the resulting mixed strategy equilibria for $\left(\frac{a_{\mathrm{L}}}{a_{\mathrm{H}}}\right)^{r}<r<\infty$, even though Baye, Kovenock, and de Vries (1994) characterize some properties of the solution. 
Since $r>0,0 \geq s<0.5$, and $a_{\mathrm{H}}>1$, we can simplify the above condition and obtain

$$
\left.4 a_{\mathrm{H}}-r-a_{\mathrm{H}} r+a_{\mathrm{H}}^{r}\left(-4+r+a_{\mathrm{H}} r\right)\right)>0,
$$

which is satisfied for any $a_{\mathrm{H}}>1$ and $0<r<1+\left(\frac{1}{a_{\mathrm{H}}}\right)^{r}$. 